\title{
The pathophysiology of mitochondrial disease as modeled in the mouse
}

\author{
Douglas C. Wallace ${ }^{1}$ and WeiWei Fan \\ Organizational Research Unit for Molecular and Mitochondrial Medicine and Genetics, University of California at Irvine, Irvine, \\ California 92697, USA
}

It is now clear that mitochondrial defects are associated with a plethora of clinical phenotypes in man and mouse. This is the result of the mitochondria's central role in energy production, reactive oxygen species (ROS) biology, and apoptosis, and because the mitochondrial genome consists of roughly 1500 genes distributed across the maternal mitochondrial DNA (mtDNA) and the Mendelian nuclear DNA (nDNA). While numerous pathogenic mutations in both mtDNA and nDNA mitochondrial genes have been identified in the past 21 years, the causal role of mitochondrial dysfunction in the common metabolic and degenerative diseases, cancer, and aging is still debated. However, the development of mice harboring mitochondrial gene mutations is permitting demonstration of the direct cause-and-effect relationship between mitochondrial dysfunction and disease. Mutations in nDNA-encoded mitochondrial genes involved in energy metabolism, antioxidant defenses, apoptosis via the mitochondrial permeability transition pore (mtPTP), mitochondrial fusion, and mtDNA biogenesis have already demonstrated the phenotypic importance of mitochondrial defects. These studies are being expanded by the recent development of procedures for introducing mtDNA mutations into the mouse. These studies are providing direct proof that mtDNA mutations are sufficient by themselves to generate major clinical phenotypes. As more different mtDNA types and mtDNA gene mutations are introduced into various mouse nDNA backgrounds, the potential functional role of mtDNA variation in permitting humans and mammals to adapt to different environments and in determining their predisposition to a wide array of diseases should be definitively demonstrated.

\section{Mitochondrial medicine}

The first evidence that mitochondrial dysfunction could yield a clinical phenotype came from the study of a young

[Keywords: Mitochondrion; mtDNA; OXPHOS dysfunction; mitochondrial disease; mouse model]

${ }^{1}$ Corresponding author.

E-MAIL dwallace@uci.edu; FAX (949) 824-6388.

Article is online at http://www.genesdev.org/cgi/doi/10.1101/gad.1784909. woman with nonthyroidal hypermetabolism associated with abnormal mitochondria and mitochondrial dysfunction (Luft et al. 1962). Subsequent studies reported mitochondrial structural and biochemical abnormalities in the muscle of patients with encephalomyopathies, leading to the histopathological diagnosis of ragged red muscle fibers (RRFs) or mitochondrial myopathy (DiMauro 1993). However, the absence of fundamental knowledge about the biology and genetics of the mitochondrion limited a deeper understanding of the inheritance and pathophysiology of mitochondrial diseases.

Studies in the 1970s and 1980s began to lay the ground work for a deeper appreciation for the complexities of mitochondrial genetics. Isolation and molecular characterization of the human mitochondrial DNA (mtDNA) provided a new understanding of the replication and transcription of the mtDNA (Montoya et al. 1981; Ojala et al. 1981; Clayton 2003), culminating in the determination of the complete mtDNA sequence and the demonstration that the function of the 13 polypeptide genes of the mtDNA are all subunits of the mitochondrial oxidative phosphorylation (OXPHOS) complexes (Anderson et al. 1981; Chomyn et al. 1985, 1986).

Concurrent studies of chloramphenicol (CAP)-resistant $\left(\mathrm{CAP}^{\mathrm{R}}\right)$ cultured human and mouse cells led to the development of the cytoplasmic hybrid (cybrid) transfer technique ultimately permitting the assignment of $\mathrm{CAP}^{\mathrm{R}}$ to the mtDNA in both mouse and human cells (Bunn et al. 1974; Wallace et al. 1975; Blanc et al. 1981a,b; Wallace 1981). The availability of the $\mathrm{CAP}^{\mathrm{R}}$ mtDNA marker then permitted the elucidation of the rules of mammalian mtDNA genetics including segregation of heteroplasmic mutations during mitotic replication, threshold expression, and complementation of mtDNA mutants (Bunn et al. 1977; Wallace et al. 1977; Wallace and Eisenstadt 1979; Oliver and Wallace 1982). Definition of the rules of mtDNA genetics culminated in the demonstration of the maternal inheritance of the human mtDNA and the discovery of extensive, regional-specific human mtDNA variation (Giles et al. 1980; Denaro et al. 1981).

These advances set the stage for the demonstration in 1988 that mtDNA deletions were present in the muscle of patients with mitochondrial myopathy (Holt et al. 1988), and that a mtDNA missense mutation was the cause of Leber Hereditary Optic neuropathy (LHON) 
(Wallace et al. 1988a). In the ensuing 20 yr, molecular defects have been observed in both mtDNA-encoded and nuclear DNA (nDNA)-encoded genes of the mitochondrial genome associated with a broad spectrum of clinical problems (Wallace et al. 2007b).

Still, the true importance of OXPHOS dysfunction in the pathophysiology of disease and the relative importance of mtDNA defects versus nDNA mitochondrial mutations in human disease remained ambiguous. These questions began to be addressed in the mid to late 1900s with the generation of mice harboring genetic defects in the nDNA-encoded (Graham et al. 1997) and mtDNA encoded OXPHOS genes (Inoue et al. 2000; Sligh et al. 2000; Fan et al. 2008).

Growing appreciation of the extent and importance of mitochondrial defects in human disease and the development of additional mouse models of mitochondrial disease have now demonstrated that OXPHOS defects have broad relevance to the genetics and pathophysiology of complex human diseases (Wallace 2008). As a result, the vibrant new field of Mitochondrial Medicine was born (Luft 1994).

\section{Mitochondrial bioenergetics}

The mitochondrion is assembled from $\sim 1500$ polypeptides, most encoded by the nDNA. However, the mtDNA still retains 13 central OXPHOS polypeptide genes. Therefore, the mitochondrial genome encompasses both mtDNA and nDNA genes and the assembly and function of mitochondrial OXPHOS requires the cooperation of both genomes.

While mutations in the nDNA-encoded mitochondrial genes frequently abide by the classical rules of Mendelian inheritance, the rules of mtDNA inheritance are quite different. Moreover, mutations in nDNA genes that affect mitochondrial biogenesis can result in mtDNA damage or dysfunction, and mtDNA mutations can modify the expression of nDNA gene variants. Hence, the interaction of the Mendelian and non-Mendelian mitochondrial genes generates a "complex genetics" that nicely explains many of the hereditary anomalies of many "common" clinical problems. Moreover, the central importance of energy metabolism for health of a variety of tissues and organs provides a direct explanation of the pathophysiology of many diseases.

\section{Mitochondrial OXPHOS}

The mitochondria generate much of the energy used by animal cells. Glucose is cleaved by glycolysis to produce pyruvate, which is converted to acetyl-Coenzyme A (CoA), $\mathrm{NADH}+\mathrm{H}^{+}$, and $\mathrm{CO}_{2}$ by pyruvate dehydrogenase (PDH). Fatty acids are oxidized by mitochondrial $\beta$ oxidation to generate acetyl-CoA, $\mathrm{NADH}+\mathrm{H}^{+}$, and $\mathrm{FADH}_{2}$, the later contained in the electron transfer factor (ETF). The acetyl-CoA enters the tricarboxylic acid (TCA) cycle, which strips the reducing equivalents (electrons from hydrogen) from organic acids to reduce $\mathrm{NAD}^{+}$to produce $\mathrm{NADH}+\mathrm{H}^{+}$. Two electrons from $\mathrm{NADH}+\mathrm{H}^{+}$are then transferred to NADH dehydrogenase (complex I).
Similarly, two electrons are collected from various organic sources and used to reduce the FAD to $\mathrm{FADH}_{2}$ in the ETF dehydrogenase, succinate dehydrogenase (SDH, complex II), and other dehydrogenases. The two electrons from complex I or from the various FAD-linked dehydrogenases then reduce ubiquinone (coenzyme $\mathrm{Q}_{10}, \mathrm{CoQ}$ ) to ubisemiquinone (CoQH.) and then to ubiquinol $\left(\mathrm{CoQH}_{2}\right)$. The electrons from $\mathrm{CoQH}_{2}$ are then transferred successively to complex III ( $b c_{1}$ complex $)$, cytochrome $c$, complex IV (cytochrome $c$ oxidase, COX), and finally to oxygen $\left(1 \frac{1}{2} \mathrm{O}_{2}\right)$ to give $\mathrm{H}_{2} \mathrm{O}$.

Each of the ETC complexes incorporates multiple electron carriers. Complexes I and II use flavins and iron-sulfur (Fe-S) centers as electron carries. The TCA enzyme aconitase also uses a Fe-S group that renders it sensitive to oxidative stress. Complex III encompasses a Fe-S center plus cytochromes $b$ and $c_{1}$ and complex IV encompasses two Cu centers plus cytochromes $a$ and $a_{3}$.

The energy that is released as the electrons flow down the ETC is used to pump protons out across the mitochondrial inner membrane through complexes I, III, and IV. This creates a proton electrochemical gradient $(\Delta \mathrm{P}=$ $\left.\Delta \Psi+\Delta \mu^{\mathrm{H}+}\right)$, a capacitor that is acidic and positive in the intermembrane space and negative and alkaline on the matrix side. The potential energy stored in $\Delta \mathrm{P}$ can be used for multiple purposes, to import proteins and $\mathrm{Ca}^{2+}$ into the mitochondrion, to generate heat, and to synthesize ATP within the mitochondrial matrix. The energy necessary to condense ADP + Pi to ATP is obtained by the flow of protons from the intermembrane space back into the matrix through the ATP synthetase (complex V). Matrix ATP is then exchanged for cytosolic ADP by the inner membrane adenine nucleotide translocators (ANTs) (Wallace 2007).

The efficiency by which dietary reducing equivalents are converted to ATP by OXPHOS is called the coupling efficiency. This is determined by the efficiency by which protons are pumped out of the matrix by complexes I, III, and IV, and the efficiency by which proton flux through complex V is converted to ATP. The uncoupler drug 2,4dinitrophenol (DNP) and the nDNA-encoded uncoupler proteins 1, 2, and 3 (Ucp1, Ucp2, and Ucp3) render the mitochondrial inner membrane leaky for protons. This short-circuits the mitochondrial inner membrane capacitor, "uncouples" electron transport from ATP synthesis, and causes the ETC to run at its maximum rate dissipating the energy as heat. Variation in mitochondrial proteins that alter the OXPHOS coupling efficiency have been proposed to determine the proportion of the calories burned by the mitochondria to generate ATP versus heat (Mishmar et al. 2003; Wallace et al. 2003; Ruiz-Pesini et al. 2004; Ruiz-Pesini and Wallace 2006).

The OXPHOS complexes are the only mitochondrial enzymes that encompass mtDNA encoded polypeptides. Complex I is assembled from 45 polypeptides, seven (ND1, ND2, ND3, ND4, ND4L, ND5, and ND6) encoded by the mtDNA; complex II is assembled from four nDNA polypeptides; complex III from 11 polypeptides, one (cytochrome $b$, cyt $b$ ) encoded by the mtDNA; complex IV from 13 polypeptides, three (COI, COLII, COLIII) from 
the mtDNA; and complex V from $\sim 17$ polypeptides, two (ATP6 and ATP8) from the mtDNA. Of the five complexes, only complexes I, III, IV, and V transport protons and these are the same complexes that retain mtDNA encoded polypeptides. Since all of the proton transporting complexes share a common electrochemical gradient $\left(\Delta \mathrm{P}=\Delta \Psi+\Delta \mu^{\mathrm{H}+}\right)$, which is central to the energetics of the cell, it is clear that the proton transport and permeability of all four complexes must be balanced to avoid one of the complexes short-circuiting the common capacitor and negating the energetic function of the other complexes. Therefore, the major electrical components of the four proton pumping complexes must coevolve. It is hypothesized that this is accomplished by retaining these proteins on the mtDNA, which is inherited from only one parent, the mother. As a result, protein genes from different mtDNA maternal lineages with different coupling efficiencies cannot be mixed by recombination (Wallace 2007).

\section{Reactive oxygen species (ROS)}

In addition to energy, mitochondrial OXPHOS also generates ROS. When the ETC becomes highly reduced, the excess electrons from complex I can be passed directly to $\mathrm{O}_{2}$ on the matrix side of the mitochondrial inner membrane or from complex III to $\mathrm{O}_{2}$ on the cytosolic side of the inner membrane to generate superoxide anion $\left(\mathrm{O}_{2}{ }^{-}\right)$. Matrix $\mathrm{O}_{2}{ }^{-}$generated by complex $\mathrm{I}$ is converted to $\mathrm{H}_{2} \mathrm{O}_{2}$ by the matrix-specific manganese superoxide dismutase (MnSOD) encoded by the nDNA Sod2 gene. Intermembrane space $\mathrm{O}_{2}{ }^{-}$from complex III is converted to $\mathrm{H}_{2} \mathrm{O}_{2}$ by the intermembrane space and cytosolic $\mathrm{Cu} / \mathrm{ZnSOD}$ (Sod1). Mitochondrial $\mathrm{H}_{2} \mathrm{O}_{2}$ can then diffuse into the nucleus cytosol. If $\mathrm{H}_{2} \mathrm{O}_{2}$ in the matrix, intermembrane space, cytosol, or nucleus encounters a reduced transition metal or is mixed with $\mathrm{O}_{2}{ }^{-}$, the $\mathrm{H}_{2} \mathrm{O}_{2}$ can be further reduced to hydroxyl radical $(\mathrm{OH} \cdot)$, the most potent oxidizing agent among the ROS.

Under normal physiological conditions, ROS production is highly regulated, at least in part controlled by complex I (Evans et al. 2000; McCord 2000; Kelley and Parsons 2001; Hansen et al. 2006; Jones 2006). However, if the respiratory chain is inhibited, then electrons accumulate on the ETC carriers, greatly increasing the rate of a single electron being transferred to $\mathrm{O}_{2}$ to generate $\mathrm{O}_{2}{ }^{-}$. Less acutely, if an individual ingests a surplus of calories (reducing equivalents), relative to his/her metabolic requirements, and their mitochondria are tightly coupled, then the $\Delta \mathrm{P}$ is driven to maximum, the ETC stalls, and the ETC electron carriers become reduced, chronically increasing $\mathrm{O}_{2}{ }^{-}$production. Over time, the excessive mitochondrial ROS production can exceed the antioxidant defenses of the mitochondrion and the nuclear cytosol and the cumulative damage can ultimately destroy the cell by necrosis or apoptosis.

\section{OXPHOS-associated functions}

ADP/ATP exchange. The ANTs exchange mitochondrial ATP for cytosolic ADP across the mitochondrial inner membrane and also regulate apoptosis. Humans have four ANT isoforms: ANT1, expressed primarily in the heart and skeletal muscle; $A N T 2$, expressed in rapidly growing cells and inducible; $A N T 3$, expressed constitutively in all tissues; and ANT4, expressed in testis. Mice have three Ant genes: Ant1, expressed in heart, skeletal muscle, and brain; Ant2, which is express in all tissues except skeletal muscle; and Ant4, expressed in testis (Levy et al. 2000; Wallace 2005c; Brower et al. 2007).

Uncoupler proteins. The mammalian uncoupler proteins (Ucp1-3) regulate mitochondrial innermembrane proton permeability and thus $\Delta \mathrm{P}$. Ucp 1 is primarily associated with thermogenesis. Mice exposed to cold induce Ucp1 in brown adipose tissue (BAT). In such a case, $\beta$-adrenergic neurons secrete noradrenaline and adrenaline that bind to the $\beta 3$-adenergic receptors on BAT cells, activating adenylylcyclase. The cAMP activates protein kinase A to phosphorylate CREB. Phosphorylated CREB enters the nucleus where it binds to cAMP response elements in the promoter of the peroxisome proliferation-activated receptor $\gamma(\operatorname{PPAR} \gamma)$ coactivator $1 \alpha$ $(\mathrm{PGC}-1 \alpha)$ gene. PGC-1 $\alpha$ interacts with brown fat transcription factors to induce Ucp1 expression. Ucp1 introduces a proton channel into the mitochondrial inner membrane, uncoupling the ETC from the ATP synthase. The ETC then starts burning the reducing equivalents stored in the fat, which directly generates heat (Nicholls and Locke 1984; Jacobsson et al. 1985; Ridley et al. 1986; Reichling et al. 1987; Kozak et al. 1988; Spiegelman and Heinrich 2004). Ucp2 and Ucp3 are more systemically expressed than $U c p 1$, and may regulate mitochondrial $\Delta \mathrm{P}$ and thus ROS production (Arsenijevic et al. 2000; VidalPuig et al. 2000).

Mitochondrial permeability transition pore ( $m t P T P)$. The mitochondria contain a self-destruct system, the mtPTP. The mtPTP is activated when the biochemical health of the mitochondria and cell decline, mitochondrial energy production declines, ROS generation increases, and/or excessive $\mathrm{Ca}^{2+}$ is released into the cytosol and is taken up by the mitochondrion. When the mtPTP is activated, it opens a channel in the mitochondrial inner membrane, short circuiting $\Delta \mathrm{P}$, and initiating programmed cell death (apoptosis).

The exact nature of the mtPTP is unknown. Until recently, it was believed that the mtPTP consisted of a complex of an ANT protein, which formed the channel spanning the mitochondrial inner membrane, and a voltagedependent anion channel (VDAC) (porin) protein, which provided the channel through the mitochondrial outer membrane. The ANTs and VDACs were then envisioned to bind to each other at inner and out membrane contact sites, forming a continuous channel. This core of ANT and VDAC proteins then interacted with the peripheral benzodiazepine receptor, which provided ligand regulation of the pore; cyclophilin $\mathrm{D}$, which monitored matrix $\mathrm{Ca}^{2+}$ concentration; mitochondrial creatine phosphokinase, which monitored intermembrane space high-energy phosphate levels; and the pro- and anti-apoptotic proteins of the $\mathrm{Bax} / \mathrm{Bcl} 2$ protein family that regulated pore activation 
and the initiation of apoptosis (Zamzami and Kroemer 2001). However, the generation of mouse cell lines and mice with genetic defects in the Ant, Vdac, and cyclosporine D (Pipf) genes have failed to fulfill the predictions of this model (Kokoszka et al. 2004; Baines et al. 2005; Basso et al. 2005; Nakagawa et al. 2005; Krauskopf et al. 2006). Therefore, the structure of the mtPTP remains unclear.

The activation of the mtPTP not only results in the collapse of $\Delta \mathrm{P}$, it causes the the release of cytochrome $c$ (cyt $c$ ), procaspase-9, apoptosis-initiating factor (AIF), and endonuclease $\mathrm{G}$ from the mitochondrial intermembrane space into the cytosol. The former two interact with cytosolic Apaf1 to activate the caspase cascade that degrades the cellular proteins. The latter two are transported to the nucleus and degrade the chromatin. In this way, cells with defective mitochondria are degraded from the inside out, stopping the release of the mitochondrial bacterialike antigens into the circulation (Wallace 2005c).

Mitochondrial dynamics. The mitochondria within a mammalian cell are in constant motion and undergoing repeated rounds of fusion and fission. Mitochondrial fusion and fission not only merges mitochondrial inner and outer membranes but also mixes mitochondria matrices and redistributes the mtDNAs.

The mammalian mitochondrial fusion machinery involves three major proteins: mitofusin 1 (Mfn1), Mfn2, and the Optic Atrophy-1 Protein (Opa1). All three proteins belong to the dynamin superfamily and contain a GTPase domain. Mfn1 and Mfn2 have similar structures and are both anchored to the mitochondrial outer membrane with most of the protein protruding into the cytosol. Opal is anchored within the mitochondrial inner membrane and protrudes in the mitochondrial intermembrane space, and appears to also anchor on the base of the mitochondrial cristae folds. During apoptosis, Opal is cleaved permitting the cristae to open and facilitating cytochrome $c$ release (Chen et al. 2003, 2005; Cipolat et al. 2004).

Components of the mitochondrial fission pathway include dynamin-related protein 1 (Drp1), fission stimulating protein 1 (Fis1), and mitochondrial fission factor (Mff). Drp1, a dynamin family GTPase, is partly cytosolic and partly located in the mitochondrion with a portion located at the mitochondrial division sites. Fis1 is an integral mitochondrial outer membrane protein, with its $\mathrm{N}$ terminus facing the cytosol. Mff is anchored to the mitochondrial outer membrane through its $\mathrm{N}$ terminus (Smirnova et al. 2001; James et al. 2003; Yoon et al. 2003; Gandre-Babbe and van der Bliek 2008).

\section{Mitochondrial genetics and diseases}

\section{Mitochondrial genes and mtDNA genetics}

The nDNA encodes all of the mitochondrial biogenesis, structural, and intermediate metabolism functions of the mitochondrial genome. Critical nDNA-encoded mitochondrial biogenesis genes include the mtDNA polymer- ase $\gamma(P O L G)$, RNA polymerase (POLRMT), mtDNA transcription factors, ribosomal proteins, and elongation factors. Mutations in many of these genes have been found to affect the mtDNA and mitochondrial OXPHOS. Similarly, the nDNA encodes OXPHOS subunits, antioxidant genes, and apoptosis-related functions, mutations in a number of which have been found to impinge on OXPHOS and the mtDNA. These nDNA-mtDNA interaction results in the nonclassical inheritance patterns associated with metabolic and degenerative diseases (Wallace 1992, 2005c, 2007; Wallace et al. 2007b). Therefore, to understand the genetics and pathophysiology of complex diseases, it is essential that we understand the genetics of the mtDNA.

The mtDNA is a double-stranded, closed-circular molecule of 16,569 base pairs (bp) in human and 16,301 bp in mouse. In mammals, the two strands of the mtDNA differ in their distribution of Gs and Cs, resulting in a C-rich light (L) strand and a G-rich heavy (H) strand. The gene arrangement of all mammal mtDNAs is conserved. In addition to the 13 polypeptide genes, the mtDNA encodes a $12 \mathrm{~S}$ and 16S rRNA, 22 tRNAs, and a mtDNA "control region" (CR). The CR encompasses the promoters for both $\mathrm{H}$ - and L-strand transcription, as well as the origin of H-strand replication. The origin of L-strand replication is located two-thirds of the way around the mtDNA in a clockwise direction. All of the rRNA and polypeptide genes are located on the H-strand, except the ND6 gene that is located on the L-strand. The tRNAs punctuate the genes, and the mature transcripts are generated from the polycistronic transcript by cleavage of the tRNAs from the transcript followed by poly adenylation (Anderson et al. 1981; Montoya et al. 1981; Ojala et al. 1981; Wallace et al. 2001).

The mtDNA genes have a much higher mutation rate than the nDNA genes, perhaps in part due to the mtDNA's proximity to the mutagenic mitochondrial ROS. The mutation rate of the human mtDNA has been estimated at from $\sim 3 \times 10^{-6}$ to $\sim 2.7 \times 10^{-5}$ per base per generation, whereas the mutation rate of the human nDNA is thought to be $\sim 2.5 \times 10^{-8}$ per base per generation (Nachman et al. 1996; Schriner et al. 2000).

Each mammalian cell contains hundreds of mitochondria and thousands of mtDNAs. When a mutation arises in mtDNA, it creates a mixed population of normal and mutant mtDNAs, a state known as heteroplasmy. When a heteroplasmic cell divides, the two types of mtDNAs are randomly distributed into the daughter cells and over time drift toward a predominance of normal or mutant mtDNAs. Ultimately, this replicative segregation results in segregation of the normal and mutant mtDNA into pure mtDNA forms, a state termed homoplasmy (Wallace 2007). As the percentage of mutant mtDNAs increases, mitochondrial energetic function decreases. When energy output is insufficient for normal tissue function, a threshold is crossed, symptoms appear, and apoptosis may be initiated (Wallace 2005b; Wallace et al. 2007b).

The human and mouse mtDNAs are strictly maternally inherited (Avise et al. 1979; Giles et al. 1980). Only one case of paternal transmission of the human mtDNA 
has been reported. This patient presented with mitochondrial myopathy and his muscle was found to contain some of his father's mtDNA, but with an additional pathogenic mutation (Schwartz and Vissing 2002).

\section{$m t D N A$ replication and transcription}

The mtDNA is replicated by the POLG, which has a molecular mass of $140 \mathrm{kDa}$ and harbors polymerase, $3^{\prime}-5^{\prime}$ exonuclease, and 5'-deoxyribose phosphate (dRP) lyase activities (Falkenberg et al. 2007). An accessory subunit of $55 \mathrm{kDa}$ markedly extends its processivity /Vermulst et al. 2008a). POLG also participates in repairing of mtDNA damage and its $3{ }^{\prime}-5^{\prime}$ exonuclease proofreading activity assures high fidelity (Trifunovic et al. 2004).

MtDNA transcription originates from two H-strand and one L-strand promoters in the CR. The transcription machinery encompasses a POLRMT, a transcription factor A (TFAM), and two other transcription factors B1 and B2 (TFB1M and TFB2M). Mammalian POLRMT is homologous to the RNA polymerase found in T3/T7 family of bacteriophage (Falkenberg et al. 2002). TFAM contains two HMG-box domains, through which it can bind, wind, and bend DNA without sequence specificity (Fisher et al. 1992). It also contains a C-terminal tail region, which is important for specific DNA recognition and transcription initiation (Dairaghi et al. 1995). Both TFB1M and TFB2M can trigger transcription in the presence of POLRMT and TFAM, with the TFB2M having an $\sim 10$-fold greater activity than TFB1M (Falkenberg et al. 2002). In addition, both TFB1M and TFB2M have rRNA methyltransferase activity, although this activity is not required for transcription initiation (McCulloch and Shadel 2003). The mtDNA transcriptional apparatus also includes mitochondrial termination factors. One, mTERF enhances rRNA transcription by binding $3^{\prime}$ to the 16 rRNA gene within the tRNA ${ }^{\text {Leu(UUR) }}$ gene and the $\mathrm{H} 1$ transcription initiation site (Martin et al. 2005). In addition, the most conserved member of the mTERF family, mTERF3, negatively regulates transcription initiation (Linder et al. 2005; Park et al. 2007).

\section{mtDNA diseases}

Most patients with mtDNA diseases caused by deletions that cross two or more gene boundaries (intergenic mutation) generally do not reproduce. Therefore, most intergenic mutations arise de novo, resulting in sporadic disease (Holt et al. 1988). Common presentations of this class of diseases include chronic progressive external ophthalmoplegia (CPEO) and the Kearns-Sayre syndrome (KSS) (Moraes et al. 1989). In contrast, most maternally inherited mtDNA diseases are the result of mutations confined within the gene commonly involving one or few base changes (intragenic mutations). Examples of this latter class of mtDNA mutations include LHON (Wallace et al. 1988a), the Myoclonic Epilepsy and Ragged Red Fiber (MERRF) syndrome (Wallace et al. 1988b; Shoffner et al. 1990), and neurogenic muscle weakness, ataxia, and retinitis pigmentosum (NARP) and Leigh syndrome (Holt et al. 1990).
The pathogenicity of mtDNA intergenic deletions is thought to be the result of the deletion of one or more tRNAs that punctuate the mtDNA genes by tRNA genes resulting in protein synthesis defects (Wallace et al. 2001). MtDNA rearrangement syndromes are invariably heteroplasmic, and can result in phenotypes of different severities depending on the distribution and of the deleted mtDNA and its percentage in each cell type. The most severe mtDNA rearrangement disease is the Pearson marrow/pancreas syndrome (Rotig et al. 1988). These patients develop pancytopenia early in life and become transfusion-dependent (Kapsa et al. 1994). If a Pearson patient survives the pancytopenia, he will progress to the next most severe disease, the KSS (Rotig et al. 1995). KSS and CPEO are associated with ophthalmoplegia, ptosis, and mitochondrial myopathy with RRF and COXnegative and SDH-hyperreactive muscle fiber zones. The pathological muscle fibers contain high concentrations of rearranged mtDNAs (Mita et al. 1989; Wallace et al. 2001; Wallace and Lott 2002; Wallace 2005c). The mildest mtDNA intergenic rearrangement phenotype is diabetes and deafness. This rearrangement phenotype is distinctive in that it can be maternally inherited. This is because the inherited rearranged mtDNAs contain a duplication. Hence, no genes are lost. However, in post-mitotic tissues, the duplicated mtDNAs give rise to deleted mtDNAs, presumably through recombination (Ballinger et al. 1992, 1994). Therefore, the differences in the clinical phenotypes of patients with intergenic deletions is not the product of the actual location of the rearrangements but rather if the rearrangement is an insertion or a deletion, the diversity of tissues that contain the rearrangement, and the percentage of mtDNAs harboring the rearrangement in each tissue (Wallace et al. 2001; Wallace and Lott 2002).

Intragenic base substitutions are more commonly maternally inherited, and can result from base substitution mutations in either polypeptide genes or in protein synthesis genes. Common polypeptide missense mutations cause LHON, which is most often the result of an ND4 missense mutation at nucleotide A11778G causing a R340H amino acid substitution (Wallace et al. 1988a) and the NARP and Leigh syndromes caused by an ATPase6 T8993G gene mutation resulting in a L156P replacement (Holt et al. 1990). Common protein synthesis mutations include the MERRF syndrome resulting from an A8344G base substation in the $t R N A^{\text {Lys }}$ gene mutation (Wallace et al. 1988b; Shoffner et al. 1990) and Mitochondrial Encephalomyopathy and Stroke-Like Episodes (MELAS) syndrome caused by an A3243G substitution in the $t R N A^{\text {Leu(UUR) }}$ gene (Goto et al. 1990). Over 200 pathogenic mtDNA base substitution mutations have been identified associated with a broad spectrum of clinical phenotypes, including encephalomyopathy, mitochondrial myopathy, and exercise intolerance, gastrointestinal syndromes, dystonia, diabetes, deafness, cardiomyopathy, Alzheimer's disease (AD), Parkinson's disease (PD), etc. (Wallace et al. 2007b).

Mutations in the mtDNA have also been associated with cancer. Both somatic and germline mtDNA mutations 
have been reported in renal adenocarcinoma, colon cancer cells, head and neck tumors, astrocytic tumors, thyroid tumors, breast tumors, prostate tumors, etc. (Wallace 2005a; Brandon et al. 2006). An important factor in carcinogenesis appears to be mitochondrial ROS production. Introduction of the pathogenic human mtDNA ATP6 T8993G mutation into prostate cancer cells has been shown to increase prostate tumor growth in association with increased mitochondrial ROS production (Petros et al. 2005). Furthermore, a mtDNA ND6 G13997A mutation was found to increase the metastatic potential of a mouse cell line in association with overproduction of mitochondrial ROS (Ishikawa et al. 2008).

\section{Adaptive mtDNA variants}

The high mtDNA mutation rate is not only responsible for generating new deleterious mutations, it has also resulted in the accumulation of numerous commonly occurring mtDNA sequence variants found in various human populations. Since the maternally inherited mtDNA cannot recombine, the mtDNA can only change by the sequential accumulation of mutations along radiating maternal lineages. This results in the generation of related mtDNA haplotypes descended from a single founder mtDNA, resulting groups of related haplotypes referred to as haplogroups. In indigenous populations, haplogroups correlate strongly with the geographic origin of the population studies (Wallace et al. 1999, 2003; Mishmar et al. 2003; Ruiz-Pesini et al. 2004; Ruiz-Pesini and Wallace 2006).

Approximately one-quarter to one-third of mtDNA polypeptide and structural RNA sequence variants found in the general population appear to be functionally important. These observations have led to the hypothesis that functional mtDNA variants that altered mitochondrial OXPHOS coupling efficiency, membrane potential, ROS production, etc. can be beneficial in certain environments and thus have permitted individuals with these mtDNAs to increase in number in that environment. Because all mtDNA variants are in total linage disequilibrium, natural selection for an adaptive mtDNA mutation would enriched all of the linked mtDNA sequence variants, which in turn would then be shared with all of the haplogroup descendants (Mishmar et al. 2003; Wallace et al. 2003; Ruiz-Pesini et al. 2004; Ruiz-Pesini and Wallace 2006).

A survey of the mtDNA sequence variation in populations from around the world has revealed that two-thirds to three-quarters of all African mtDNAs belong to macrohaplogroup L. All European mtDNAs belong to macrohaplogroup N, which gave rise to the European haplogroups $\mathrm{H}, \mathrm{I}, \mathrm{J}, \mathrm{Uk}, \mathrm{T}, \mathrm{U}, \mathrm{V}, \mathrm{W}$, and $\mathrm{X}$. Asian mtDNAs belong to either macrohaplogroup $\mathrm{M}$ or $\mathrm{N}$, both $\mathrm{M}$ and $\mathrm{N}$ giving rise to multiple haplogroups including $C, D, E, G$, etc. for $M$ and $\mathrm{A}, \mathrm{B}, \mathrm{F}$, etc. for $\mathrm{N}$. Of all of the Asian haplogroups, only A, C, and D are enriched in northeastern Siberia, and these crossed over the Bering land bridge into the Americans to found the Native American populations. These Native American haplogroups were subsequently joined by haplogroups B and X (Wallace et al. 1999; Wallace 2005c).

Today, the metabolic diversity associated with these ancient adaptive mtDNA variants appears to be influencing individual predisposition to a wide spectrum of common diseases. Haplogroup $\mathrm{H}$ correlates with reduced risk of age-related macular degeneration, while haplogroups J and $U$ are associated with increased risk of macular degeneration as well as increased drusen levels and retinal pigment abnormalities (Jones et al. 2007; Udar et al. 2009). Haplogroup H and H-nt 4336 are associated with increased risk, and haplogroups J and Uk with decreased risk, for developing PD (Shoffner et al. 1993; van der Walt et al. 2003; Ghezzi et al. 2005; Khusnutdinova et al. 2008). The haplogroup H-nt 4336 sublineage is also associated with increased $\mathrm{AD}$ risk, while haplogroups $\mathrm{U}$ and $\mathrm{T}$ are associated with decreased risk in certain contexts (Shoffner et al. 1993; Chagnon et al. 1999; Carrieri et al. 2001; van der Walt et al. 2004). Haplogroup $J$ was then correlated with longevity in Europeans (Ivanova et al. 1998; De Benedictis et al. 1999; Rose et al. 2001; Niemi et al. 2003) and D with longevity in Asians (Tanaka et al. 1998, 2000). Haplogroup J has been associated with increased risk of diabetes in certain European descent populations (Mohlke et al. 2005; Crispim et al. 2006; Saxena et al. 2006), while haplogroup N9a is protective of diabetes, metabolic syndrome, and myocardial infarction in Asians (Fuku et al. 2007; Nishigaki et al. 2007; Wallace et al. 2007a). Haplogroup $U$ has been associated with increased serum IgE levels (Raby et al. 2007), while haplogroup $\mathrm{H}$ has been associated with protection against sepsis (Baudouin et al. 2005). Haplogroups J and U5a are associated with more rapid AIDS progression while H3, Uk, and IWX retard AIDS progression (Hendrickson et al. 2008). Halogroup $\mathrm{H}$ is protective against lipodystrophy associated with highly active anti-retrovial therapy (HAAT), while haplogroup $\mathrm{T}$ may increase risk of lipodystrophy (Hendrickson et al. 2009). Finally, various haplogroups have been correlated with altered risk for particular cancers (Gottlieb and Tomlinson 2005; Wallace 2005a; Booker et al. 2006; Brandon et al. 2006; Bai et al. 2007; Darvishi et al. 2007). Therefore, mtDNA functional variation modulates predisposition to a wide range of metabolic and degenerative disease, cancer, and longevity.

\section{Somatic mtDNA mutations and the interaction of $m t D N A$ variants}

In addition to recent deleterious mutations and ancient adaptive mtDNA variants, somatic mtDNA mutations play an important role in human health. Both intergenic and intragenic mtDNA mutations have been found to accumulate with age in post-mitotic tissues (Cortopassi and Arnheim 1990; Corral-Debrinski et al. 1992; Soong et al. 1992; Michikawa et al. 1999; Murdock et al. 2000). Moreover, somatic mtDNA intergenic and intragenic mutation levels are elevated in the organs of patients with degenerative diseases (Corral-Debrinski et al. 1991, 1994; Horton et al. 1995; Coskun et al. 2004; Bender et al. 2006; Kraytsberg et al. 2006). Since these mutations 
accumulate on post-mitotic tissues with age, and their rate of accumulation would be expected to rise with increased ROS production and thus in cells with mitochondrial defects, it follows that the accumulation of somatic mtDNA mutations causes an age-related decline in mitochondrial function, thus exaserbating partial inborn defects in mitochondrial function leading to the delayed-onset and progression course of age-related diseases. Thus, somatic mtDNA mutations provide the aging clock.

Therefore, the three types of mtDNA sequence variants interact to influence human health: (1) recent deleterious mtDNA mutations that result in maternally inherited diseases (Wallace and Lott 2002; Wallace 2005c), (2) ancient population-specific adaptive variants that predispose to disease (Mishmar et al. 2003; Wallace et al. 2003; Ruiz-Pesini et al. 2004; Ruiz-Pesini and Wallace 2006), and (3) somatic mtDNA mutations that progressively erode mitochondrial function (Wallace 2005c, 2007). Therefore, one source of genetic complexity in common diseases is the interaction of these three mtDNA genetic factors. This was first observed with the demonstration that European haplogroup J increased the penetrance of the milder European pathogenic LHON mtDNA mutations (Brown et al. 1995, 1997, 2002; Torroni et al. 1997).

\section{Diseases of nDNA OXPHOS gene and nDNA-mtDNA variant interactions}

A wide array of pathogenic mutations has been identified in nDNA-encoded mitochondrial OXPHOS structural (Procaccio and Wallace 2004) or assembly genes such as the complex IV (COX) assembly genes Surf1 (Tiranti et al. 1998; Zhu et al. 1998) or Cox10 (Antonicka et al. 2003). The more severe nDNA mitochondrial gene mutations present as a lethal childhood Leigh syndrome, but symptoms can be mild, as depression (Wallace et al. 2007b).

Milder nDNA mutations may also interact with milder mtDNA mutations to create a sever disease. In a family in which the sons of two sisters were found to have severe mitochondrial cardiomyopathy and a complete absence of skeletal muscle complex I, a missense mutation was found in the nDNA, X-linked, complex I, polypeptide gene NDUFA1 (G32R). However, the NDUFA1 mutation only reduced the complex I activity by $\sim 30 \%$. Further analysis revealed that the mtDNA of these two boys also harbored two complex I missense mutations: ND1 T3368C (M21T) and ND5 T12599C (M88T). In cybrids, this mtDNA also reduced complex I function $\sim 30 \%$. Therefore, it was surmised that these boys were severely affected because they inherited both the nDNA NDUFA1 and the ND1 and ND5 missense mutations from their mothers, the combination of the two generating a lethal biochemical defect (Potluri et al. 2009).

\section{Mitochondrial diseases of nDNA-mtDNA interaction}

A whole series of diseases have now been defined in which mutations in the nDNA-encoded genes for mitochondrial biogenesis result in the destabilization of the
mtDNA with symptoms ranging from mild neurological complications to lethal Alper syndrome. Mutations in the mtDNA POLG (15q25) or Twinkle helicase (10q21) are associated with multiple mtDNA deletions and have been linked to autosomal dominant or recessive PEO (AD/ARPEO) (Spelbrink et al. 2001; Van Goethem et al. 2001). Inactivation mutations in ANT1 (14q34) results in autosomal recessive myopathy and cardiomyopathy without PEO associated with multiple mtDNA deletions (Palmieri et al. 2005). Certain missense mutations in ANT1 also cause autosomal dominant $\mathrm{PEO}$, associated with the accumulation of multiple mtDNA deletions (Kaukonen et al. 1995). Mutations in deoxyguanosine kinase (2q13) and mitochondrial thymidine kinase 2 (16q21) result in mtDNA depletion (Mandel et al. 2001; Saada et al. 2001) and mutations in succinyl-CoA synthase subunit SUCLA2 cause mild methylmalonic aciduria, Leigh-like encephalomyopathy, dystonia and deafness in association with mtDNA depletion (Carrozzo et al. 2007). Mutations in the cytosolic thymidine phosphorylase (chromosome 22q13) cause Mitochondrial Neurogastointestinal Encephalomyopathy (MNGIE) (Nishino et al. 1999) associated with mtDNA deletions and depletion.

Mutations in the mitochondrial fusion proteins have also been linked to disease, with and without mtDNA instability. Mutations in the OPA1 gene cause autosomal dominant optic atrophy (Delettre et al. 2000), while mutations in the mitofusin $2(M f n 2)$ gene result in CharcotMarie-Tooth Type 2A2, a peripheral neuropathy, (Zuchner et al. 2004).

\section{Mouse models of OXPHOS disease}

A number of the features of OXPHOS disease have been recapitulated by the genetic manipulation of the mouse. Informative mouse models have been reported for the inactivation of OXPHOS genes including the ADP/ATP carrier gene Ant1, the uncoupling protein genes Ucp1-3, the complex I structural gene Ndufs4, the electron carrier gene $c y t c$, and the complex IV assembly genes Surf1 and Cox10. Additional insight has been obtained from the modification of the mitochondrial antioxidant genes GPX1, Sod1, and Sod2; the mitochondrial fusion genes $M f n 1, M f n 2$, and Opa1; and the mitochondrial biogenesis genes Polg, Twinkle, Tfam, and Mterf3.

While development of mouse models of nDNA encoded mitochondrial disease have progressed rapidly, investigation of the effects of mtDNA mutations have lagged behind due to lack of robust technologies to modify the mtDNA of the mouse. Even so, several mouse models have been generated containing various mtDNA variants. These include a heteroplasmic 4696-bp rearrangement, different strain and species mtDNAs (xenomitochondrial mice), a 16S rRNA T2433C mutation, an ND6 13885 C insertion frameshift mutation, and a COI T6589C missense mutation.

\section{Modification of nDNA OXPHOS genes}

The effects of limiting mitochondrial ATP output on tissue and organ function have been investigated by 
inactivation of the Ant isoform genes. The inactivation of Ant1 in mouse resulted in the complete loss of Ant in the skeletal muscle, a partial deficiency in the heart, but normal Ant levels in the liver, as confirmed by the ADP stimulation of respiration rate (Graham et al. 1997). The skeletal muscle of $A n t 1^{-/-}$mice exhibit massive proliferation of mitochondria, increased $\mathrm{SDH}$ and $\mathrm{COX}$ staining in skeletal muscle fibers, RRFs, degeneration of the contractile fibers, and marked exercise fatigability, the composite phenotype known as mitochondrial myopathy. The hearts of these mice develop a striking hypertrophic cardiomyopathy with proliferation of cardiomyocyte mitochondria (Graham et al. 1997). MITOCHIP and differential display gene expression analysis of $A n t 1^{-1-}$ skeletal muscle revealed a coordinate upregulation of the mtDNA polypeptide and rRNA genes; selected nuclear-encoded OXPHOS genes; mitochondrial regulatory genes $P G C-1 \alpha, N r f-1, T f a m$, and myogenin; and stress response genes including $M c l 1$. In contrast, glycolytic genes, proapoptotic genes, and c-myc were all down-regulated (Murdock et al. 1999; Subramaniam et al. 2008).

The inactivation of Ant-mediated ADP/ATP exchange deprives the ATP synthase of ADP substrate, stopping the ATP synthesis and blocking proton flux back into the mitochondrial matrix through the ATP synthase. Consequently, $\Delta \mathrm{P}$ becomes hyperpolarization; complexes I, III, and IV cannot pump against the maximized $\Delta \mathrm{P}$; and the ETC stalls. As a result, ROS production was increased sixfold to eightfold in $A n t 1^{-/-}$skeletal muscle and heart mitochondria. In skeletal muscle, the increased oxidative stress was paralleled by a sixfold increase in mitochondrial MnSOD level and a threefold increase in mitochondrial Gpx1 level. In the heart, where the Ant deficiency is incomplete, Gpx1 is increased threefold, but MnSOD was not up-regulated (Esposito et al. 1999). Finally, the hearts of 16- to 20-mo-old Ant $1^{-1-}$ mice show a striking increase in mtDNA rearrangement levels (Esposito et al. 1999). The generation of the Ant1-deficient mouse established the phenotype expected for a null Ant1 mutation (Graham et al. 1997), which exactly anticipated the phenotype that was to be found 8 years later in ANT1null human patients (Palmieri et al. 2005).

Inactivation of the testis-specific Ant isoform, Ant4 (Linder et al. 2005; Rodic et al. 2005) caused a severe defect in spermatogenesis (Brower et al. 2007). The testes of the Ant4 $4^{-1-}$ mice are much smaller than normal, though testicular development is normal until $\sim 17 \mathrm{~d}$ after birth. After that, the number of spermatocytes declines dramatically rendering the males infertile. While the general spermatogenesis marker Dazl and the early spermatogenesis marker Dmc1 were normally expressed in $A n t 4^{-1-}$ testes, the late spermatogenesis markers $A-M y b, D v 13$, and $S y c p 3$ were significantly reduced and the spermatocyte markers HoxA4 and CyclinA1 are undetectable. Apoptotic spermatocytes are observed by both TUNEL labeling and caspase-3 staining. Ant2 is up-regulated in the $A n t 4^{-1-}$ testis, and this may provide sufficient energy for early spermiogenesis. However, the dramatic decline in spermiogenesis after day 17 indicates that mitochondrial energy production is essential after this point (Brower et al. 2007).

Mice deficient in the Ucp1 are cold-sensitive and accumulate excess fat in BAT. However, they do not become obese. This may be because Ucp2 mRNA is upregulated in BAT and epididymal fat and partially compensates for loss of Ucp1 expression (Enerback et al. 1997).

Ucp2 knockout mice have a normal response to cold and are not obese. However, they have a markedly increased resistance to Toxoplasma gondii infection, which forms cysts in the brain. Toxoplasma is eliminated by macrophages by oxidative burst, and $U c p 2^{-1-}$ macrophages produced more ROS then $U c p 2^{+/+}$macrophages. This is associated with an elevated expression of interluekin-1B (Il16) and MnSOD. Therefore, Ucp2 inactivation appears to increase mitochondrial ROS production perhaps by maximizing $\Delta \mathrm{P}$ and ETC electron density (Arsenijevic et al. 2000).

$U c p 3$ inactivation in mouse was associated with the up-regulation of $U c p 1$ and $U c p 2$ in BAT. In the skeletal muscle, Ucp3 inactivation increased the state $3 /$ state 4 respiration ratio due to a decrease in state 4 respiration and hence proton leakage. In addition, skeletal muscle $\mathrm{O}_{2}{ }^{-}$production was increased by $58 \%$ and muscle mitochondrial aconitase was reduced by $20 \%$ (Vidal-Puig et al. 2000). Therefore, Ucp3 appears to function in muscle to regulate ROS production by partially uncoupling OXPHOS.

Inactivation of the complex I Ndufs 4 structural gene in mouse resulted in a partial defect in respiratory complex I. Ndufs $4^{-1-}$ mice appear grossly healthy up to day 30, although smaller than age matched controls. However, after $30 \mathrm{~d}$ of age the $N d u f s 4^{-1-}$ mice became lethargic and their body temperature declined $\sim 2^{\circ} \mathrm{C}$. The animals were also blind, showed an absence of B waves in electroretinograms, and failed to recognize a visual cliff. Starting around $35 \mathrm{~d}$ of age, these mice show a rapid decline in startle response and develop severe ataxia. Between day 35 and 50, the Ndufs $4^{-1-}$ mice stopped gaining weight, developed more severe ataxia, and finally died. Complex I-dependent respiration was reduced $>50 \%$ in $\mathrm{Ndufs}_{S} 4^{-/-}$ liver mitochondria but complex II- or IV-dependent respiration was not affected. Blue native gel electrophoresis (BNGE) showed significantly reduced complex I protein levels, though no difference was found in muscle mitochondrial ATP levels and respiration. Histochemical analysis of muscle revealed dramatically reduced complex I activity with normal complex II and IV activities, although muscle morphology and mitochondrial ultrastructure remained unchanged (Kruse et al. 2008). Thus, inactivation of the mouse Ndufs 4 gene resulted in a Leigh-like phenotype.

Genetic inactivation of the cytochrome c (cytc) gene in the mouse $\left(c y t c^{-1-}\right)$ resulted in embryonic lethality by embryonic day 10.5 (E10.5). While severely growthretarded, $c y t c^{-/-}$embryonic development continued through day E8.5, with all three germ layers arising $(\mathrm{Li}$ et al. 2000). Cells cultured from E8.5 embryos were viable if the medium was supplemented with uridine and pyruvate 
(King and Attardi 1989). However, the NF-кB, PI3K/Akt, and JNK cell survival pathways were not activated in cytc $^{-/-}$cells, and the death-receptor pathway was hyperactivated by TNF $\alpha$. The $c y t c^{-/-}$cells were resistant to staurosporin, UV irradiation, and serum deprivation induction of apoptosis, as monitored by DNA fragmentation and chromatin condensation and did not generate the Apaf-1, cyt $c$, procaspase-9 apoptosome ( $\mathrm{Li}$ et al. 2000). Thus, $c y t c^{-/-}$mice revealed that the mitochondrial ETC is not only necessary for generating ATP to sustain growth by also important in regulation of growth, differentiation, and apoptosis.

Inactivation of the mouse COX assembly gene, Surf1, was achieved by either replacement of exons 5-7 with a neomycin resistance cassette (Surf $1^{\mathrm{NeO}-l-}$ ) (Agostino et al. 2003) or by insertion of a loxP sequence into exon 7 generating a stop codon at amino acid position 225 , thus eliminating 81 C-terminal amino acids (Surf $1^{\text {loxp }-1-}$ ) (Dell'agnello et al. 2007). The Surf $1^{\text {Neo- }-}$ mice had a $\sim 90 \%$ embryonic lethality. Of the live pups, $\sim 25 \%$ died within $2 \mathrm{~d}$ after birth, $\sim 20 \%$ died within $2 \mathrm{mo}$, and $\sim 35 \%$ survived past 12 mo or more. Rotarod and grip strength tests revealed significantly reduced motor activity, coordination, and muscle strength and endurance. Both male and female Surf $1^{\mathrm{NeO}-1-}$ mice showed reduced fertility. COX activity was reduced to $23 \%-40 \%$ of normal in different tissues. While the expression levels of individual COX subunits were not affected by Surf1 ${ }^{\text {Neo }}$ inactivation, the amount of fully assembled COX was significantly reduced and COX assembly intermediates increased. Histochemical analysis also showed decreased COX activity and increased SDH activity in Surf1 $1^{\mathrm{Neo-}-\text { - }}$ skeletal muscle and liver (Agostino et al. 2003).

The Surf $1^{\text {loxp-l- }}$ mice exhibit no embryonic lethality and had a normal survival rate. Mutant pups were significantly smaller at birth but gained the weight back upon weaning. Similar to the Surf $1^{\mathrm{Neo-}-}$ mice, the Surf $1^{\text {loxp- }-1-}$ mice had a $50 \%-70 \%$ reduction of COX activity as well as reduced amount of fully assembled COX in different tissues. Their skeletal muscle had decreased COX and increased SDH histochemical staining. Surprisingly, the Surf $1^{10 x p-1-}$ mice had an increased life span with the median life span of $793 \mathrm{~d}$ as compared with $654 \mathrm{~d}$ for the controls. The mutant mice did not develop neurological defects but rather showed resistance to $\mathrm{Ca}^{2+}$ mediated excitotoxic brain damage. Isolated Surf $1^{\text {loxp-l- }}$ neurons also showed reduced glutamate-induced cytosolic $\mathrm{Ca}^{2+}$ influx and resulting cell death, which was due to reduced mitochondrial $\mathrm{Ca}^{2+}$ uptake. The Surf $1^{\text {loxp-l-}}$ mitochondria had normal morphology and membrane potential (Dell'agnello et al. 2007).

While both Surf1 inactivation strategies reduced COX assembly and activity, the difference in their phenotypes was striking. Perhaps the neo-protein in the Surf1 locus is toxic. Alternatively, the truncated 255-amino-acid product in Surf $1^{\text {loxp-l- }}$ mice might have been beneficial, perhaps by causing partial uncoupling.

The COX assembly protein, Cox10, was selectively inactivated in mouse muscle, neurons, and liver (Diaz et al. 2005, 2008; Fukui et al. 2007). Muscle-specific
Cox10-depleted animals develop a regressive myopathy and weakness, starting the age of 3 mo and leading to death at between 4 and 10 mo. The COX activity was only $\sim 12 \%$ of controls at the age of $1 \mathrm{mo}$ and $\sim 2 \%$ at $7 \mathrm{mo}$. Histochemical analysis confirmed the progressive decline in COX activity and increased SDH activity in muscle, along with the development of RRFs and abnormal mitochondria (Diaz et al. 2005).

In the neuron-specific Cox10-depleted animals, both COX activity and assembly in the cortex and hippocampus progressively declined starting at $\sim 1 \mathrm{mo}$. By $\sim 4 \mathrm{mo}$, the mutant mice showed behavioral defects including biphasic hyper- and hypoactivities, compulsive devouring behavior, tail vibration, and excessive sensitivity to external stimuli accompanied by size shrinkage and reduced cell density of the forebrain. Majority of these mice lived for only 8-10 mo. Crossing with an $\mathrm{AD}$ mouse model expressing mutant amyloid precursor protein $(A P P)$ and presenilin 1 (PSEN1) genes in brain resulted in a reduction in amyloid plaque formation and $A \beta$ generation, as well as decreased oxidative damage to proteins and nucleic acids (Fukui et al. 2007).

Liver-specific inactivation of Cox10 caused mitochondrial hepatopathy similar to what is found in some children with mitochondrial disease. These mice show reduced body weight and activity, and start dying between 45 and $65 \mathrm{~d}$. They had severe liver dysfunction, with reduced COX activity, increased SDH activity, increased mitochondrial proliferation and lipid accumulation, reduced stored glycogen, and diminished ATP levels (Diaz et al. 2008).

\section{Inactivation of nDNA antioxidant genes}

The phenotypic effects of altering mitochondrial antioxidant genes have been investigated by the genetic inactivation of the Sod1, Sod2, or Gpx1 genes in mouse. Mice deficient in Cu/ZnSOD (Sod1) show no overt abnormities during development and in early adulthood. These mice have a reduced life span, develop liver tumors by 20 mo of age, and exhibit significantly increased numbers of mitochondria and elevated lipofuscin granules in their hepatocytes. The MnSOD activity in Sod1 ${ }^{-1-}$ mice is increased $\sim 24 \%$ at 3 and $6 \mathrm{mo}$, but declines to $\sim 70 \%$ of the controls by the end of life in association with increased protein oxidation, DNA damage, and lipid peroxidation. Gpx 1 activity is reduced by $40 \%$ at $3 \mathrm{mo}$, and the apurinic/apyrimidinic endonuclease/redox factor1 (APE1/Ref1 ${ }^{\text {Red/Ox) }}$ is down-regulated at 3 mo but subsequently up-regulated by 6-18 mo. Sod $1^{-1-}$ liver exhibits widespread oxidative damage, resulting in a $\sim 72 \%$ reduction in cytosolic aconitase activity and a fourfold reduction in aconitase protein levels (Elchuri et al. 2005). These mice also develop retinal dysfunction associated with drusen, thickened Bruch's membrane, and choroidal neovascularization, key elements of age-related macular degeneration (Imamura et al. 2006; Hashizume et al. 2008). These abnormalities are associated with increased oxidative damage of retinal pigment epithelium and disruption of $\beta$-catenin-mediated cellular integrity of retinal pigment 
epithelium (Imamura et al. 2006). The thickness of both retinal outer nuclear cell layer and inner nuclear cell layer decline gradually after $10 \mathrm{wk}$ and became disorganized by 15 mo. These changes were associated with swollen nuclei, vacuolized cytoplasm, disrupted plasma and nuclear membranes in the retinal inner nuclear layer, and disordered nuclei alignment, damaged mitochondria, and swollen cell bodies in the retinal outer nuclear layer (Hashimoto et al. 2001).

Inactivation of the mouse MnSOD (Sod2) gene (Li et al. 1995; Lebovitz et al. 1996) results in much more severe consequences than the Sod1 inactivation (Reaume et al. 1996). Two independent Sod2 mutant mouse strains have been created: one on a CD1 background (Li et al. 1995) and the other on a C57BL6/J2 (B6) background (Lebovitz et al. 1996). The Sod2 ${ }^{-1-}$ CD1 mice develop a dilated cardiomyopathy at about $8 \mathrm{~d}$ of age (Li et al. 1995) while the Sod2 $2^{-T-}$ B6 mice develop a basal ganglia and brain stem degeneration of the large neurons and die at $\sim 18 \mathrm{~d}$ (Lebovitz et al. 1996). One reason for the phenotypic difference between the two strains might prove to be the absence of a nicotinamide nucleotide transhydrogenase (Nnt) gene in B6 mice (Freeman et al. 2006; Huang et al. 2006).

Sod2 $2^{-1-}$ CD1 mice develop massive lipid deposition in the liver, marked deficiency in complex II (SDH), and a partial complex I and citrate synthase deficiency in the heart. Mitochondrial aconitase was almost completely inactivated in the heart and brain (Li et al. 1995). Thus, the increased mitochondrial $\mathrm{O}_{2}{ }^{-}$appears to inactivate all of the mitochondrial Fe-S center containing enzymes, blocking the TCA cycle and ETC, which inhibits mitochondrial fatty acid oxidation. This results in fat deposition in the liver and energy starvation in the heart, leading to cardiac dilation and failure (Melov et al. 1999). Sod2-deficient mice show a $40 \%$ reduction in state III respiration, with $\mathrm{ADP}$ stimulated respiration rates in isolated mitochondria of about 1.6-fold in the first ADP addition (state III respiration). However, there was no stimulation of respiration on subsequent ADP or uncoupler additions, possibly because these neonatal animals show a markedly increased tendency toward activation of the mtPTP (Kokoszka et al. 2001), presumably due to the chronic $\mathrm{O}_{2}{ }^{-}$exposure. When the sensitized mtPTP is exposed to the transient drop in $\Delta \mathrm{P}$ following $\mathrm{ADP}$ stimulation of the ATP synthase or uncoupler addition, the mtPTP must open causing the release of mitochondrial matrix cofactors and cytochrome $c$, disrupting respiration (Cai et al. 2000). The Sod2 $2^{-1-}$ animals also develop methylglutaconic acuidurea, suggesting reduced liver HMG-CoA lyase activity, and increased oxidative damage to their DNA, with the greatest extent being found in the heart, followed by brain, and then liver (Melov et al. 1999).

Inactivation of the mouse Gpx1 gene reduces mitochondrial energy output. GPx1 is strongly expressed in the liver, brain, and renal cortex, but very weakly expressed in the heart and skeletal muscle. GPX1 $1^{-1-}$ mice are viable, but show a $20 \%$ reduction in body weight, indicating chronic growth retardation. The liver mito- chondria of $G P \times 1^{-1-}$ mice secrete fourfold more $\mathrm{H}_{2} \mathrm{O}_{2}$ than wild-type mitochondria. However, the mutant heart mitochondria do not secrete increased $\mathrm{H}_{2} \mathrm{O}_{2}$ (Esposito et al. 2000), presumably because the heart mitochondria contain catalase (Radi et al. 1991, 1993a,b). The respiratory control ratio (RCR) and the power output (state III rate times the $\mathrm{P} / \mathrm{O}$ ratiol levels of $G p \times 1^{-/-}$mice are reduced by a third in the liver mitochondria, but were normal in heart mitochondria (Esposito et al. 2000).

The importance of mitochondrial $\mathrm{H}_{2} \mathrm{O}_{2}$ production in mammalian health and aging has been confirmed by the generation of transgenic mice in which catalase is retargeted from the peroxisome to the mitochondrial matrix. This is accomplished by addition of an $\mathrm{N}$-terminal mitochondrial import peptide to the catalase cDNA and inactivation of the peroxisomal targeting sequence. The resulting mitochondrial-catalase (mCAT) transgenic animals exhibit a $20 \%$ increase in mean life span and a $10 \%$ increase in maximum life span. Histological analysis revealed reduced cardiac defects in mCAT mice. Heart mitochondria of the mCAT mice are more resistant to $\mathrm{H}_{2} \mathrm{O}_{2}$-induced inactivation of aconitase and produce $25 \%$ less $\mathrm{H}_{2} \mathrm{O}_{2}$. Their skeletal muscle was protected against oxidative damage to total DNA and mtDNA, and accumulated 50\% less mtDNA rearrangement mutations in middle-aged animals. Therefore, mitochondrial ROSinduced damage to mtDNA is an important factor in determining longevity (Schriner et al. 2005).

\section{Probing the mtPTP}

Genetic inactivation of the Ant, Vdac, and cyclosporine $\mathrm{D}$ (Pipf) genes in the mouse has been used to probe the structure and function of the mtPTP. However, these studies failed to fulfill predictions of the classical mtPTP model (Zamzami and Kroemer 2001). Both Ant1 and Ant2 were inactivated in mouse liver by breeding onto an Ant $1^{-/-}$background an X-linked Ant2 gene flanked by loxP sites $\left(A n t 2^{\text {LoxP }}\right)$ together with an alb-cre. The complete absence of Ants was confirmed by the lack of ADP stimulation of respiration and the marked elevation of $\Delta \mathrm{P}$, with Ucp2 protein levels virtually undetectable. Complex IV activity and COI and cytochrome $c$ protein levels were all increased, consistent with their up-regulation to compensate for a complete OXPHOS ATP deficiency. Even though all of the Ants were eliminated from the liver mitochondria, the mtPTP could still be induced to undergo mtPTP permeability transition by increased $\mathrm{Ca}^{2+}$ and reduced $\Delta \mathrm{P}$, resulting in collapse of the mitochondrial inner membrane $\Delta \mathrm{P}$ and mitochondrial swelling. Cultured Ant1- and Ant2-deficient hepatocytes were also shown to be capable of apoptosis. Hence, the mtPTP still exists in the absence of Ants, meaning that the Ants are not the obligate inner membrane channel. The Antdeficient mtPTPs are different, however, being more resistant to $\mathrm{Ca}^{2+}$ activation and insensitive to modulation by the Ant ligands, adenine nucleotides and carboxyatractyloside (Kokoszka et al. 2004).

Genetic inactivation of VDACs also failed to eliminate the mtPTP. Mice have three VDAC genes (Vdac1-3), all of 
which have been inactivated. While Vdac2 deficiency led to embryonic lethality (Cheng et al. 2003), Vdac1- and Vdac3-deficient mice appear normal (Baines et al. 2007). The basic properties of the mtPTP in Vdac1 and Vdac3deficient mice were indistinguishable from those of control mitochondria. Three different stimuli (carbonyl cyanide-p-trifluoromethoxyphenylhydrazone (FCCP), phenylarsine oxide (PhAsO), and N-ethylmaleimide (NEM)) and three different inhibitors (cyclosporine A, ubiquinone $\mathrm{O}$, and Ro68-3400) all had the same effect on the mtPTP of Vdac1-deficient mitochondria as on control mitochondria (Krauskopf et al. 2006).

Vdac1- and Vdac3-deficient mice were found to develop some muscle defects and ultrastructural abnormalities (Anflous et al. 2001). Vdac3-deficient muscle pathology included reduced mitochondrial ETC complexes; enlarged, abnormally shaped mitochondria; and extended intermyofibrillar growth. Moreover, the males are infertile. While the testicular size and weight, the apoptosis rates, and the number of sperm number per epididymus are all normal, the sperm proved to be immotile. Electron microscopy of the sperm show enlarged and disordered mitochondria. More importantly, the axonemes are structurally abnormal, often being deficient in one of the $9+2$ microtubule doublets (Sampson et al. 2001). This links the mitochondria to the integrity of the cilial basal body.

Like the situation with Ants, inactivation of the mouse cyclophilin D Pipf gene alters regulation of the mtPTP without eliminating the pore. Cyclophilin D-deficient mice are overall normal, and their mitochondria show no change in respiration rate. However, mtPTP activation by low doses of $\mathrm{Ca}^{2+}$ was blocked, though high doses of $\mathrm{Ca}^{2+}$ still can result in mtPTP opening. Other inducers of the permeability transition, such as $\mathrm{H}_{2} \mathrm{O}_{2}$ and atractyloside, were also unable to trigger mtPTP opening in cyclophilin D-deficient mitochondria. Cyclophilin D-deficient cells respond normally to proapoptotic stimuli but show high resistance to oxidative stress and $\mathrm{Ca}^{2+}$ overload induced necrotic cell death in vitro and ischemia/reperfusion induced cell death in vivo (Baines et al. 2005; Basso et al. 2005; Nakagawa et al. 2005).

\section{Inactivation of the nDNA mitochondrial dynamics genes}

The mitochondrial fusion genes $M f n 1, M f n 2$, or Opa1 have all been inactivated in the mouse. When homozygous, all of the mutants were embryonic lethal (Chen et al. 2003; Davies et al. 2007). The cerebellum-specific inactivation of $M f n 1$ or $M f n 2$ was achieved by crossing $M f n 1^{\operatorname{Lox} P}$ or $M f n 2^{\operatorname{Lox} P}$ mice with mice expressing a cerebellum-specific promoter cre recombinase-driven (pMeox2-cre). Mfn1 inactivation in the cerebellum resulted in mice with normal growth, development and fertility. However, cerebellum-specific inactivation of Mfn2 gene resulted in one-third of the mice dying at day 1 postnatally and the surviving animals showing severe defects in movement and balance (Chen et al. 2007). The cerebellum of the Mfn2-deficient mice was $25 \%$ the size of control at postnatal days 15-17, associ- ated with reduced and deteriorating Purkinje cells (PC) and increased apoptosis of granule cells. Mitochondrial complex $\mathrm{V}$ and cytochrome $c$ are increased during cerebellar deterioration, suggesting a compensatory induction to counter mitochondrial energy deficiency. Mutant Purkinje cells grew poorly in vitro, and the cell number declined dramatically within $14 \mathrm{~d}$ to $2 \%$ that of controls. The surviving mutant Purkinje cells had an abnormal morphology; shorter, thinner, and less branched dendritic trees; and far fewer spines. The mitochondria of the mutant Purkinje cells tended to cluster in the cell body, not entering the dendritic tracts. Mfn2 mutant Purkinje cells also showed major alterations in mitochondrial morphology, distribution, and cristae organization and content, associated with decreased mitochondrial complex I and IV activities and increased complex II activity. Transfection with a Lentivirus carrying either the $M f n 1$ or Mfn2 gene rescued the defective phenotype in Mfn2 knockout Purkinje cells, confirming that the defect was in mitochondrial fusion, not due to a novel feature of Mfn2 (Chen et al. 2007).

Two mouse strains deficient in Opa1 have been isolated by N-ethyl-N-nitrosourea (ENU) mutagenesis: an $\sim 1065+5$ G-to-A mutation in intron 10 causing exon 10 skipping (Alavi et al. 2007), and a C1051T transition in exon 8 converting Glu 285 to a stop codon (Davies et al. 2007). When homozygous, both mutants was embryonic lethal. In the heterozygous state they showed vision loss at $\sim 1$ yr of age and some behavioral abnormalities. Retinal histology revealed a significant age-related decline in retinal ganglion cell number through $13 \mathrm{mo}$ and a complete loss of large axons, disorganized structure, irregular myelination of axons, formation of membranous whorls, loss of myelin sheets, increased collageneous material, decreased number of neurofibrils, and morphologically abnormal mitochondria with disorganized cristae. Punctuated and dispersed mitochondria were also observed in the muscle cells (Alavi et al. 2007; Davies et al. 2007).

\section{Modification of the nDNA biogenesis genes}

In addition to mitochondrial myopathy and cardiomyopthy, the inactivation of the mouse Ant 1 gene resulted in the accumulation of multiple mtDNA deletions (Graham et al. 1997). This destabilization of the mtDNA in the Ant1-deficient mice parallels the observations of multiple mtDNA deletions seen in both autosomal recessive (Palmieri et al. 2005) and autosomal dominant (Kaukonen et al. 2000) human ANT1 disease patients. ANT deficiency might cause mtDNA rearrangements because of nucleotide precursor limitation of increased mtDNA damage for the excessive ROS production.

Alterations in mouse mitochondrial biogenesis genes also result in mtDNA damage and pathological phenotypes. Replacement of the mouse Polg loci with a proofreading-deficient Polg created a "mtDNA mutator" mouse strain, which has increased mtDNA mutation rate and reduced longevity (Trifunovic et al. 2004; Kujoth et al. 2005; Vermulst et al. 2007, 2008b). The median life 
span of the mtDNA mutator mice is $\sim 48 \mathrm{wk}$, with the maximum age of $61 \mathrm{wk}$. Body weight reduction is noted at $\sim 24$ wk of age, and at $\sim 40-45 \mathrm{wk}$, the mtDNA mutator mice show reduced body size, kyphosis, reduced hair density and alopecia. By $\sim 20-25$ wk of age, they show reduced fat content, bone marrow density, spleen enlargement, and extramedullary haematopoiesis in the liver. By $\sim 40 \mathrm{wk}$, they show enlarged cardiac left ventricle cavity, COX deficiency, and abnormal mitochondria in some cardiomyocytes. Infertility is found in both males and females, associated with smaller testes and reduced epididymis sperm content in males. These premature aging phenotypes are accompanied with reduced full-length mtDNAs, increased deleted mtDNAs, and increased mtDNA base substitution mutations (Trifunovic et al. 2004; Vermulst et al. 2007, 2008b). Therefore, the rate of accumulation of somatic mtDNA mutations determines longevity.

Introduction of altered mtDNA helicase (Twinkle) genes into the mouse partially recapitulated human mutant phenotypes (Spelbrink et al. 2001; Tyynismaa et al. 2005). Two different adPEO Twinkle gene mutations have been introduced into the mouse: a Thr 360 alanine (Twinkle ${ }^{A T}$ ) missense mutation and an in-frame duplication of amino acid 353-365 (Twinkle dup). While the Twinkle ${ }^{A T}$ transgenic mice only show a mild myopathy phenotype, the Twinkle dup mice show characteristic histological features of late-onset mitochondrial myopathy with $\mathrm{COX}^{-}$muscle fibers observed at 12 mo. Electron microscopy reveals mildly affected fibers with mitochondrial enlargement and proliferation, and severely affected fibers in which the myofibrillar structure is replaced by enlarged mitochondria with concentric cristae, identical to those seen in the skeletal muscle of PEO patients. Mitochondria are also frequently seen in autophagosomes. Twinkle dup mice became COX-deficient and developed mitochondrial proliferation in cerebellar Purkinje cells, hippocampal CA2 pyramidal neurons, and neurons of indusium griseum. While no biochemical OXPHOS deficiency could be detected, this is probably because homogenization of the tissue mixes the mitochondrial OXPHOS enzymes of individual cells, each with a different OXPHOS defect. The net result is that the average mitochondrial defect is only partially in the homogenate. Multiple mtDNA deletions have been detected in Twinkle dup brain but not in heart, with a $3-\mathrm{kb}$ mtDNA predominating in $\mathrm{COX}^{-}$ fibers of Twinkle dup muscle. The heart and muscle of Twinkle dup mice showed normal mtDNA copy number but the brain had a $37 \%-46 \%$ reduction in mtDNA levels (Tyynismaa et al. 2005).

Genetic manipulation of the nuclear-encoded mitochondrial transcription factor, TFAM, has provided evidence for the mitochondrial role in a variety of degenerative diseases. Systemic inactivation of mouse Tfam proved to be embryonic lethal, while heterozygous $\mathrm{Tfam}^{+/-}$animals were viable and reproductively competent (Larsson et al. 1998). The homozygous $\mathrm{Tfam}^{-1-}$ mice died between E8.5 and E10.5, with a complete absence of the Tfam protein, and severely reduced or a complete absence of mtDNA. They were also deficient in COX, but not SDH, and had enlarged mitochondria with abnormal cristae. The heterozygous mice had a $50 \%$ reduction in Tfam transcript and protein, a $34 \%$ reduction in mtDNA copy number, a $22 \%$ reduction in mitochondrial transcripts, and a partial reduction in the COI protein level in heart, but not in liver (Larsson et al. 1998).

Mice with heart- and muscle-specific inactivation of Tfam died postnatally due to dilated cardiomyopathy with a mean age of $20 \mathrm{~d}$. They developed cardiac conduction defects with a prolongation of the PQ interval and intermittent atrioventricular block. The heart and muscle showed reduced Tfam protein and mtDNA transcript levels, a $26 \%$ reduction in heart mtDNA, a $60 \%$ reduction in skeletal muscle mtDNA, and a reduction of respiratory complexes I and IV (COX), but not complex II (SDH). Histochemical analysis of the hearts revealed some COX-negative and SDH-hyperreactive cardiomyocytes. However, no alterations could be detected in the skeletal muscle (Wang et al. 1999).

A skeletal muscle-specific Tfam inactivation in mouse resulted in a progressive myopathy starting at 3-4 mo, with scattered atrophic fibers, numerous RRF, COXdeficient fibers, and markedly enlarged mitochondria with distorted cristae. The muscle pathology correlated with a loss of Tfam, reduced mtDNA and mitochondrial transcript levels, and decreased respiratory chain function and ATP production. Citrate synthase activity was increased in the skeletal muscle, suggesting a compensatory up-regulation of mitochondrial mass to offset the respiratory chain defect. Absolute muscle force was reduced with the extensor digitorum longus muscle being more affected than the soleus muscle. Thus, the skeletal muscle-specific Tfam knockout mouse reproduces the key pathophysiological features found in human mitochondrial myopathy patients (Wredenberg et al. 2002).

Selective inactivation of the Tfam gene in mouse midbrain dopaminergic (DA) neurons led to a PD phenotype. By 6 wk, these mice showed decreased mitochondrial COI expression in DA neurons of substantia nigra (SN) and the ventral tegmental area (VTA). At $\sim 14$ wk of age they experienced a progressive decline of locomotion, rearing, and exploratory behavior, associated with a progressive loss of midbrain DA neurons and striatal DA nerve terminals. A single dose of L-DOPA markedly improved the motor dysfunction. Intraneuronal inclusions (Lewy bodies), a key pathological feature of PD, was detected in 6-wk-old mutant mice in most midbrain DA neurons. Furthermore, at $11 \mathrm{wk}$, the midbrain neurons showed typical mitochondrial membrane structures incorporated into the inclusions, and immunostaining analysis revealed the presence of the $\alpha$ subunit of mitochondrial ATP synthase, partially overlapped with the inclusions. These results support the hypothesis that mitochondrial dysfunction results in PD and raises the possibility that damaged mitochondria nucleate Lewy body formation (Ekstrand et al. 2007).

Pancreatic $\beta$-cell-specific inactivation of mouse Tfam resulted in diabetes. The $\mathrm{Tfam}^{-/-} \beta$-cells had greatly reduced COX activity but normal SDH activity, and contain highly abnormal giant mitochondria. The mutant 
mice developed mitochondrial diabetes in two stages. They exhibited increased blood glucose in both fasting and nonfasting states starting at about $5 \mathrm{wk}$ of age. Subsequently, they show a progressive decline in $\beta$-cell mass and a decreased ratio of endocrine to exocrine pancreatic tissue. The younger animals were diabetic because their $\beta$ cells could not secrete insulin, but the older animals lost many of their $\beta$ cells. However, the $\beta$-cell loss did not seem to be the product of apoptosis, since the number of TUNEL-positive cells was not increased. The mitochondria of the mutant islets showed decreased $\Delta \mathrm{P}$ and the glucose-induced intracellular $\mathrm{Ca}^{2+}$ oscillations were severely dampened (Silva et al. 2000). This model strongly implicates mitochondrial dysfunction in the etiology of diabetes.

Inactivation of other genes involved in mitochondrial transcription also led to mitochondrial dysfunction. Inactivation of the Mterf3 gene (Linder et al. 2005) resulted in embryonic lethality. Heart- and muscle-specific inactivation of Mterf3 results in increased heart size, abnormal mitochondria with reduced respiratory chain function, and a reduced life span of only $18 \mathrm{wk}$. However, the mtDNA level was normal, indicating that Mterf3 is not involved in mtDNA replication. Steady-state levels of mitochondrial encoded transcripts from both L-strand and $\mathrm{H}$-strand promoters (LSP and HSP) were increased in $M$ terf $3^{-1-}$ heart, suggesting that Mterf3 is a repressor of mitochondrial transcription. The mutant mitochondria showed reduction in assembly levels of complex I, III, $\mathrm{IV}$, and V, all of which have mtDNA encoded subunits, whereas complex II was not affected. Enzymatic assays showed significant decrease in complex I, I + III, and IV but not complex II activity. Chromatin immunoprecipitation (ChIP) revealed that Mterf3 specifically binds to LSP and HSP regions, consistent with its inhibition of transcription initiation (Park et al. 2007). Thus, Mterf3 negatively regulates mitochondrial transcription initiation, and its loss results in mitochondrial cardiomyopathy.

\section{Introduction of mtDNA into the mouse}

Two major hurdles confront efforts to introduce mtDNA mutations into the mouse: generating mtDNA mutations and introducing these mutations into the mouse female germline. Both of these difficulties can be overcomed by breeding maternal lineages derived from female "mtDNA mutator" mice to permit the mtDNA mutations to segregate to form individual mutant mtDNA lineages. However, this approach may have two limitations: desirable polypeptide mutations may be selectively lost from the germline, and large numbers of lineages must be generated to obtained the desired mutants (Stewart et al. 2008).

Mouse mtDNA mutations. To generate the most desirable mutants, it would be optimal to generate the mutant mtDNA in vitro and then to transform the mtDNAs into the mitochondria of cultured mouse cells. Unfortunately, no reliable method for the direct transformation of cells with isolated mtDNA has yet been validated. Therefore, mouse mtDNA mutations must be isolated by mutagenesis and selection of mouse cells. Once the desired mtDNA mutation has been isolated, then it must be introduced into the mouse female germline, either via embryonic stem cells or single-cell embryo cybrid transfer (Bunn et al. 1974; Wallace et al. 1975).

Several methods have been developed for isolating mouse cells harboring deleterious mtDNA mutations. The first was to isolate mouse cells resistant to mitochondrial inhibitors. Mouse cells resistant to CAP, a mitochondrial ribosome inhibitor, harbor a T2433C mutation in the mitochondrial 16S rRNA that inhibits mitochondrial protein synthesis and partially inhibits mitochondrial complexes I, III, and IV (Bunn et al. 1974; Blanc et al. 1981b). Mouse cell lines have also been isolated resistant to mitochondrial complex III inhibitors anti-mycin A, myothiazol, HQNO, and stimatelin (Howell et al. 1987; Howell and Gilbert 1988) and found to contain cytochrome $b$ mutations (Howell 1990). Cells resistant to the complex I inhibitor rotenone, have also been isolated and found to contain mutations in the ND6 or ND5 genes (Bai and Attardi 1998; Bai et al. 2000). In the ND6 mutation, a C was inserted within the six Cs at nucleotides 13,88513,890 , causing a frameshift and stop codon at amino acid position 79. When homoplasmic, this mutation resulted in loss of complex I assembly, a 90\% decrease of complex I-dependent (malate/glutamate) respiration, and a 99\% reduction in complex I activity (Bai and Attardi 1998). The ND5 C12087A mutation changed Arg 115 to a stop codon. At $\sim 96 \%$ heteroplasmy, this mutation caused a severe complex I defect (Bai et al. 2000).

Mutations in the mtDNA have also been generated by exposure of mouse cells to trimethylpsoralen followed UV irradiation. The heteroplasmic cells are then treated with ethidium bromide (EtBr) to reduce the mtDNA copy number. The $\mathrm{EtBr}$ is then removed to permit the clonal expansion of the mutant mtDNAs. The resulting clones are screened for respiratory deficiency based on the ability to grow on glucose but not galactose (Acin-Perez et al. 2004). With this method, a homoplasmic G15263A (glutamate 373 lysine) was isolated in the $c y t b$ gene that disrupted complex III assembly and also reduced complex I assembly and activity (Acin-Perez et al. 2004).

Spontaneous mtDNA mutations can also arise during prolonged cell culture. A L929 mouse cell line was found to contain three mtDNA mutations, including a heteroplasmic C6063A (Leu 246 isoleucine) mutation in the COI gene, a homoplasmic T6589C (Val 421 alanine) COI mutation, and a heteroplasmic $\mathrm{C}$ insertion at nucleotides 13,885-13,890 in the ND6 gene causing a frameshift (Bai and Attardi 1998; Acin-Perez et al. 2003). These mtDNA mutations have been segregated by EtBr-induced mtDNA depopulation-repopulation and characterized. Biochemical studies showed that the COI T6589C single base mutation results in a $65 \%$ reduction of complex IV activity, but when combined with the COI C6063 mutation the COX defect is reduced to $38 \%$. Thus, the C6063A COI mutation may act as a suppressor of the T6589C COI mutation (Acin-Perez et al. 2003). 
mtDNA mutations can also be rescued from aged mouse tissues. Somatic mtDNA mutations, including point mutations, deletions, and rearrangements, have been shown to accumulate in post-mitotic tissues with age (Wallace et al. 2007b). Mitochondria-containing synaptosomes can then be isolated from aged mouse brains and fused to mouse cells that have been grown in EtBr to select for cells that lack mtDNA $\left(\rho^{\circ}\right)$. The $\rho^{\circ}$ cells are glucose, uridine, and pyruvate auxotrophs, so cells acquiring functional mitochondria by transmitochondrial cybrid fusion can be selected in medium lacking uridine and/or pyruvate (King and Attardi 1989; Inoue et al. 2000; Trounce et al. 2000).

mtDNA mutations into the mouse maternal germline. To date, two basic procedures have been successful at introducing exogenous mtDNA mutations into the mouse female germline: (1) fusion of cytoplasts from mutant cells directly to mouse single-cell embryos and implantation of the embryos into the oviduct of pseudopregnant females, and (2) fusion of enucleated cell cytoplasts bearing mutant mtDNA to undifferentiated female mouse embryonic stem (fmES) cells, injection of the stem cell cybrids into mouse blastocysts, and implantation of the chimeric embryos into a foster mother. The former method was used to create mice harboring a heteroplasmic mtDNA deletion (Inoue et al. 2000), while the latter has permitted the creation of variety of mouse strains bearing heteroplasmic or homoplasmic mtDNA base substitution mutations (Sligh et al. 2000; McKenzie et al. 2004; Kasahara et al. 2006; Fan et al. 2008).

mtDNA rearrangement mice. A mouse model of mtDNA rearrangement disease has been generated by recovering a rearranged mtDNA from mouse brain by synaptosome fusion, and then fusion of cytoplasts from rearranged mtDNA cell line to single-cell mouse embryos (Inoue et al. 2000). The rearranged mtDNA contained a 4696-bp deletion that removes six tRNAs and seven structural genes. Animals were obtained having 6\%$42 \%$ deleted mtDNAs in their muscle. Females with $6 \%-13 \%$ deleted mtDNAs were mated, and the rearranged mtDNAs were transmitted through three successive generations, with the percentage of deleted mtDNAs increasing with successive generations to a maximum of $90 \%$ in the muscle of some animals. While mtDNA duplications were not observed in the original synaptosome cybrid cells, they were found in the post-mitotic tissues of the heteroplasmic animals. Therefore, the maternal transmission of this rearranged mtDNA may be through a duplicated mtDNA intermediate, as observed in a human maternal diabetes mellitus and deafness (Ballinger et al. 1994). While RRFs were not observed in these animals, fibers with $>85 \%$ mutant mtDNAs were COX-negative, and many fibers had aggregates of subsacolemmal mitochondria. The heart tissue of heteroplasmic animals was also mosaic for both COX-positive and COX-negative fibers, and the amount of lactic acid in peripheral blood was proportional to the amount of mutant mtDNA in the muscle tissues. Mice with pre- dominantly mutant mtDNAs in their muscle tissue die within $200 \mathrm{~d}$ of systemic ischemia and enlarged kidneys with granulated surfaces and dilation of the proximal and distal renal tubules. These animals also developed high concentrations of blood urea and creatinine (Inoue et al. 2000). Mice containing $\geq 70 \%$ of the deleted mtDNAs became infertile and developed oligospermia and asthenozoospermia, suggesting a strong requirement of the active respiration for mouse spermatogenesis (Nakada et al. 2006). Hence, mice harboring mtDNA rearrangement mutations have been created, but the phenotypes and inheritance patterns are somewhat different from those seen in most human mtDNA rearrangement patients.

$m t N Z B$ and $m t C A P^{R}$ mice. To establish a general protocol for the introduction of exogenous mtDNAs into the mouse female germline, advantage was taken of the fact that most inbred mouse strains from North America were derived from the same founding female and thus have the same "common" mtDNA haplotype. In contrast, NZB mice, which were inbred from Swiss mice, have mtDNAs differing from this common haplotype by $\sim 100$ nucleotide (nt) substitutions (Ferris et al. 1982), one of which creates a BamHI restriction site polymorphism. Synaptosomes have been isolated from NZB mice by homogenization of the brains and purification of the mitochondria-containing cellular fragments through the Percoll gradient centrifugation. The NZB synaptosomes were then fused to the mouse $\mathrm{TK}^{-}, \rho^{\mathrm{O}}$ cell line LMEB4 (Trounce et al. 2000) and the resulting LMEB4(mtNZB) cybrids were selected in bromodeoxyuridine and in medium lacking uridine (Trounce et al. 2000). The LMEB4(mtNZB) cybrids were then enucleated, and the cytoplasmic fragments, cytoplasts, fused to the CC9.3.1 fmES cells of the 129SvEvGpilc origin that had been treated with the mitochondrial toxin, rhodamine 6G (R6G) to deplete the resident mitochondria. The resulting CC9.3.1(mtNZB) cybrids were injected into C57BL/6J (B6) mouse embryos and mice with a high degree of chimerism generated. One female chimeric mouse transmitted the heteroplasmy to her daughter, and this female transmitted the heteroplasmic mtDNAs to all of her female lineage descendants over multiple generations (Sligh et al. 2000; MacGregor et al. 2006).

This fmES cell protocol has also been used to introduce $\mathrm{CAP}^{\mathrm{R}}$ mtDNAs into the mouse. CC9.3.1 fmES cells were treated with R6G and fused to cytoplasts isolated from mouse 501-1 cells whose mtDNA harbored the 16S rRNA T2433C mutation (Blanc et al. 1981b). The resulting CC9.3.1 $\left(\mathrm{mtCAP}^{\mathrm{R}}\right)$ fmES cybrids with a high percentage of $\mathrm{CAP}^{\mathrm{R}}$ mtDNAs were injected into blastocysts and females with a high degree of chimerism generated. The $\mathrm{CAP}^{\mathrm{R}}$ chimeric animals developed bilateral nuclear cataracts, reduced rod and cone excitation detected by electroretinograms (ERG), and retinal hamartomatous growths emanating from the optic nerve heads. Several of the chimeric females transmitted the $\mathrm{CAP}^{\mathrm{R}} \mathrm{mtDNAs}$ to their progeny in either the homoplasmic or heteroplasmic state. The resulting $\mathrm{CAP}^{\mathrm{R}}$ progeny either died in utero or in the neonatal period. Mice born alive exhibited 
striking growth retardation, progressive myopathy with myofibril disruption and loss, dilated cardiomyopathy, and abnormal heart and muscle mitochondria morphology (Sligh et al. 2000). These phenotypes are remarkably similar to those seen in the MELAS tRNA ${ }^{\mathrm{Leu}(\mathrm{UUR})}$ A3243G patients (Heddi et al. 1999). Hence, deleterious mtDNA protein synthesis mutations can cause mitochondrial disease in the mouse with a nature and severity analogous to those seen in humans.

Xenomitochondrial mice. Using the same fmES cell technique, mtDNAs from different mouse species have been introduced into the common mouse inbred strain B6 (Mus musculus). The mtDNAs from Mus spretus and the more distantly related Mus dunni were transferred into Mus musculus $\rho^{\circ}$ cell line LMEB3 to generate homoplasmic cybrids. The cybrids were then enucleated and fused to R6G-treated CC9.3.1 fmES cells, and homoplasmic fmES cybrids containing Mus spretus or Mus dunni mtDNAs generated. These xenomitochondrial mouse cell lines were injected into blastocysts and 18 and 29 chimeras of various chimerism levels were generated. Breeding of all female chimeras resulted in one homoplasmic germline transmission of Mus spretus mtDNA and 5 homoplasmic germline transmissions of Mus dunni mtDNA. However, no breedable females were obtained to continue the germline transmission and permit in vivo mitochondrial functional analysis (McKenzie et al. 2004)

mtDNA ND6 and COI mutant mice. A homoplasmic mtDNA COI T6589C missense mutation has been successfully introduced into the mouse female germline. In one study, a homoplasmic COI mutant cell line was enucleated and fused with R6G-treated fmES cells resulting in homoplasmic mutant fmES cybrids. The COI mutant fmES cybrids were shown to have complex IV (COX) defect by cytochemistry. Chimeric females were then generated, which also gave rise to homoplasmic F1 mutant mice. F1 females were then backcrossed five times with B6 males and the resultant N6 mice were all shown to contain $100 \%$ of the COI mutation. At the age of $6 \mathrm{mo}$, (N6) COI mutant mice had lower staining of COX activity in the heart compared with age-matched $\mathrm{B} 6$ controls. Biochemical analysis confirmed the lower complex IV activity in the brain, heart, liver, and skeletal muscle of the mutant mice. Increased blood lactate level and slight growth retardation were also observed. However, no disease phenotype similar to human mitochondrial diseases was reported (Kasahara et al. 2006).

In an independent study, the same COI T6589C missense mutation was introduced into the mouse female germline along with the ND6 13885insC frameshift mutation. These linked mutations caused loss of complex I activity but increased complex II, III, and IV activities in cultured cells. After fused with R6G-treated CC9.3.1 fmES cells, four fmES cell cybrids were obtained containing $100 \%$ of the two linked mutations. However, further analysis revealed that in one fmES cybrid EC77, 4\% of the mtDNAs acquired a revertant $\mathrm{T}$ deletion adjacent to the ND6 13885 C insertion, thus restoring the normal ND6 reading frame. These EC77 fmES cybrids were then used to generate three female chimeras. The proportion of the ND6 frameshift mutation had declined from 96\% in EC77 cybrids to $63 \pm 13 \%$ in different chimeric tissues. After mating with B6 males, the three chimeras generated a total of 111 pups, of which only one pup was an agouti female, and harbored the mutant mtDNAs. The level of the ND6 frameshift mutation in this female had declined in all tissues to $47 \%$ in its tail and $44 \pm 3 \%$ in its different tissues. This mutant (F1) female was then backcrossed with B6 males and the level of the ND6 frameshift mutation declined to $14 \%$, then $6 \%$, and then to $0 \%$ within four generations. This suggests that there is an active selection against the severe ND6 frameshift mutation. Analysis of the mtDNAs from single oocytes collected from $14 \%$ females confirmed that all oocytes contained $\sim 14 \%$ frameshift mtDNAs or less, never more than the mother's mean (Fan et al. 2008).

While the ND6 frameshift mutation was quickly eliminated, the COI missense mutation remained homoplasmic in the founder F1 female and all subsequent offspring. At 12 mo old, mice containing 100\% of the COI T6589C mutation and $100 \%$ of the ND6 revertant mutation have a $50 \%$ reduction in complex IV activity in the brain, heart, liver, and skeletal muscle. Muscle histology reveals RRFs and abnormal mitochondrial characteristic of mitochondrial myopathy. In addition, echocardiographic analysis of 12 -mo-old COI mutant mice shows that $100 \%$ of the animals developed a striking cardiomyopathy. The COI mutant hearts have hypertrophic cardiomyocytes with fibrolysis, binucleate cells, and cardiac fibrosis. Some mutant hearts also exhibit evidence of inflammation, interstitial edema, and increased blood vessel number and diameter. Cardiac ultrastructural analysis revealed mitochondrial abnormalities including mitochondrial overproliferation, reduction in mitochondrial matrix density and cristolysis, and loss of myofilaments. Hence, the transmission of a single mtDNA COI T6589C missense mutation proved sufficient to cause mitochondrial myopathy and cardiomyopathy proving that mtDNA mutations can be the primary cause of degenerative diseases (Fan et al. 2008).

The differences between the mild phenotypes observed in the Japanese COI T6589C mutant mouse (Kasahara et al. 2006) relative to the American COI T6589C mutant mouse (Fan et al. 2008) might be explained in several ways. Many mtDNA mutation phenotypes are age-related, and Japanese mice were examined at 6 mo while American mice were analyzed at $1 \mathrm{yr}$. Alternatively, the nuclear backgrounds of the two COI mutant mouse strains might have been different. For example, the C57BL/6J mouse strain used in the American mouse harbors the Nnt gene mutation (Huang et al. 2006), which might exacerbate the COI defect through increased oxidative stress. Finally, the American mouse's mtDNA only contained the COI T6589C missense mutation, not the COI C6063A suppressor mutation (Acin-Perez et al. 2003). If the Japanese mouse contained both COI mutations, then the complex IV defect in the Japanese mice might have been less severe than that of the American mice. 
The Fan et al. (2008) study demonstrated that the female germline has the capacity for intraovarian selection against severely deleterious mtDNA mutations such as the ND6 frameshift mutation, while permitting transmission of more moderate mtDNA mutations such as the COI missense mutation. The same conclusion was reached by characterizing mtDNA mutations generated by the Polg "mtDNA mutator" mice. The "mtDNA mutator" mice had a substantial increase in the level of mtDNA mutations in various tissues. Base mutations were distributed evenly along the analyzed fragment, the $c y t b$ gene, with all three codon positions mutated at the same frequency (Trifunovic et al. 2004). However, when these random mtDNA polypeptide gene mutations were transmitted through the female germline into their offspring with a wild-type Polg background, a strong selection was observed against nonsynonymous mutations. The ratio of nonsynonymous substitutions per site versus synonymous substitutions per site drops to 0.6035 , far less than the value of one indicative of no selection. First and second codon position mutations were also underrepresented, relative to third codon positions, another indicator for negative selection. On the other hand, a variety of tRNA mutations were transmitted through the maternal lineage (Stewart et al. 2008). Studies of mice containing the 4696-bp deletion have also shown a decrease in the levels of deleted mtDNA in female germ cells and their offspring, although the level of deleted mtDNA remained constant or increased in somatic tissues with age (Sato et al. 2007).

These observations may explain why there is a dearth of severe mtDNA base substitutions in humans and a high prevalence of more moderate pathogenic mtDNA mutations such as those causing MERRF and MELAS. It has been proposed that the primordial female germ cells have a limited number of mtDNAs permitting rapid genetic drift toward pure mutant or wild mtDNA during the $\sim 20$ female germline cell divisions (Jenuth et al. 1996). This would lead to oogonia within fetal ovigerous cords to have mtDNA genotypes symmetrically distributed around the maternal mean heteroplasmic level. At around birth the ovigerous cords reorganize to form single oogonia surrounded by granulosa cells. Of the proto-oocytes generated, only about $30 \%$ complete meiotic maturation, with the remainder undergoing apoptosis (Tilly and Tilly 1995; Hussein 2005). Since apoptosis in preovulatory follicles has been shown to be induced by increased oxidative stress (Tsai-Turton and Luderer 2006), it is conceivable that the proto-oocytes with the highest percentages of severe mtDNA mutations produce the most ROS and thus are preferentially eliminated by apoptosis.

\section{Conclusion}

The discovery of intraovarian selection of more severely deleterious mtDNA mutations demonstrates how little we know about the genetics and physiology of the human and mammalian mtDNA genetics. Therefore, it will be important to generate many more mouse lines harboring variant mtDNAs, both by cybrid fusion (Inoue et al. 2000;
Sligh et al. 2000; Fan et al. 2008) and by propagation of Polg ${ }^{\text {mut }} /$ Polg ${ }^{\text {mut }}$ generated mtDNA mutations (Stewart et al. 2008). Characterization of a wide range of mtDNA variants in the mouse can be anticipated to reveal new phenotypes associated with mitochondrial dysfunction in the same way that preparing the $A n t 1^{-/-}$mouse (Graham et al. 1997) anticipated the phenotype of a human patient with an ANT1-null mutation (Palmieri et al. 2005). In addition to establishing the importance of mtDNA variation in the well-defined metabolic and degenerative diseases, these mutations will permit investigation of the role of mitochondrial and mtDNA involvement in predisposition and resistance to infectious diseases, inflammatory disorders, cancers, dysmorphologies, and an array of other troubling phenotypes.

As a greater diversity of maternally transmitted mtDNA mutants becomes available, various mtDNA mutations can be combined with various nDNA mutants associated with mitochondrial dysfunction, metabolic and degenerative diseases and cancer predisposition to determine the importance of mtDNA modification in addition to nDNA gene penetrance and expressivity. The introduction of a greater diversity of mtDNA haplotypes from diverse mtDNA strains may also permit understanding the importance of naturally occurring mtDNA variants in mammalian physiology, adaptation to different environments, and in predisposition to disease.

These and related studies will permit determination of exactly how important the mitochondrial and mtDNAs are in determining the complex physiology and inheritance of the common "complex" metabolic and degenerative diseases that demand much of the health care resources in the developing and developed countries (Wallace 2008).

\section{Acknowledgements}

We thank Ms. Marie T. Lott for her assistance in assembling this manuscript. This work has been supported by NIH grants NS21328, AG24373, DK73691, AG13154, and AG16573; a CIRM Comprehensive Grant RC1-00353-1; a Doris Duke Clinical Interfaces Award 2005 awarded to D.C.W.; and a CIRM Predoctoral Fellowship awarded to W.F.

\section{References}

Acin-Perez R, Bayona-Bafaluy MP, Bueno M, Machicado C, Fernandez-Silva P, Perez-Martos A, Montoya J, Lopez-Perez MJ, Sancho J, Enriquez JA. 2003. An intragenic suppressor in the cytochrome c oxidase I gene of mouse mitochondrial DNA. Hum Mol Genet 12: 329-339.

Acin-Perez R, Bayona-Bafaluy MP, Fernandez-Silva P, MorenoLoshuertos R, Perez-Martos A, Bruno C, Moraes CT, Enriquez JA. 2004. Respiratory complex III is required to maintain complex I in mammalian mitochondria. Mol Cell 13: 805-815.

Agostino A, Invernizzi F, Tiveron C, Fagiolari G, Prelle A, Lamantea E, Giavazzi A, Battaglia G, Tatangelo L, Tiranti V, et al. 2003. Constitutive knockout of Surf1 is associated with high embryonic lethality, mitochondrial disease and cytochrome c oxidase deficiency in mice. Hum Mol Genet 12: $399-413$. 
Alavi MV, Bette S, Schimpf S, Schuettauf F, Schraermeyer U, Wehrl HF, Ruttiger L, Beck SC, Tonagel F, Pichler BJ, et al. 2007. A splice site mutation in the murine Opal gene features pathology of autosomal dominant optic atrophy. Brain 130: 1029-1042.

Anderson S, Bankier AT, Barrell BG, de Bruijn MH, Coulson AR, Drouin J, Eperon IC, Nierlich DP, Roe BA, Sanger F, et al. 1981. Sequence and organization of the human mitochondrial genome. Nature 290: 457-465.

Anflous K, Armstrong DD, Craigen WJ. 2001. Altered mitochondrial sensitivity for ADP and maintenance of creatinestimulated respiration in oxidative striated muscles from VDAC1-deficient mice. I Biol Chem 276: 1954-1960.

Antonicka H, Leary SC, Guercin GH, Agar JN, Horvath R, Kennaway NG, Harding CO, Jaksch M, Shoubridge EA. 2003. Mutations in COX10 result in a defect in mitochondrial heme A biosynthesis and account for multiple, early-onset clinical phenotypes associated with isolated COX deficiency. Hum Mol Genet 12: 2693-2702.

Arsenijevic D, Onuma H, Pecqueur C, Raimbault S, Manning BS, Miroux B, Couplan E, Alves-Guerra MC, Goubern M, Surwit R, et al. 2000. Disruption of the uncoupling protein-2 gene in mice reveals a role in immunity and reactive oxygen species production. Nat Genet 26: 435-439.

Avise JC, Lansman RA, Shade RO. 1979. The use of restriction endonucleases to measure mitochondrial DNA sequence relatedness in natural populations. I. Population structure and evolution in the genus Peromyscus. Genetics 92: 279-295.

Bai Y, Attardi G. 1998. The mtDNA-encoded ND6 subunit of mitochondrial NADH dehydrogenase is essential for the assembly of the membrane arm and the respiratory function of the enzyme. EMBO J 17: 4848-4858.

Bai Y, Shakeley RM, Attardi G. 2000. Tight control of respiration by NADH dehydrogenase ND5 subunit gene expression in mouse mitochondria. Mol Cell Biol 20: 805-815.

Bai RK, Leal SM, Covarrubias D, Liu A, Wong LJ. 2007. Mitochondrial genetic background modifies breast cancer risk. Cancer Res 67: 4687-4694.

Baines CP, Kaiser RA, Purcell NH, Blair NS, Osinska H, Hambleton MA, Brunskill EW, Sayen MR, Gottlieb RA, Dorn GW, et al. 2005. Loss of cyclophilin D reveals a critical role for mitochondrial permeability transition in cell death. Nature 434: 658-662.

Baines CP, Kaiser RA, Sheiko T, Craigen WJ, Molkentin JD. 2007. Voltage-dependent anion channels are dispensable for mitochondrial-dependent cell death. Nat Cell Biol 9: 550555.

Ballinger SW, Shoffner JM, Hedaya EV, Trounce I, Polak MA, Koontz DA, Wallace DC. 1992. Maternally transmitted diabetes and deafness associated with a $10.4 \mathrm{~kb}$ mitochondrial DNA deletion. Nat Genet 1: 11-15.

Ballinger SW, Shoffner JM, Gebhart S, Koontz DA, Wallace DC. 1994. Mitochondrial diabetes revisited. Nat Genet 7: 458-459.

Basso E, Fante L, Fowlkes J, Petronilli V, Forte MA, Bernardi P. 2005. Properties of the permeability transition pore in mitochondria devoid of Cyclophilin D. J Biol Chem 280: 1855818561.

Baudouin SV, Saunders D, Tiangyou W, Elson JL, Poynter J, Pyle A, Keers S, Turnbull DM, Howell N, Chinnery PF. 2005. Mitochondrial DNA and survival after sepsis: A prospective study. Lancet 366: 2118-2121.

Bender A, Krishnan KJ, Morris CM, Taylor GA, Reeve AK, Perry RH, Jaros E, Hersheson JS, Betts J, Klopstock T, et al. 2006. High levels of mitochondrial DNA deletions in substantia nigra neurons in aging and Parkinson disease. Nat Genet 38: $515-517$.
Blanc H, Adams CW, Wallace DC. 1981a. Different nucleotide changes in the large rRNA gene of the mitochondrial DNA confer chloramphenicol resistance on two human cell lines. Nucleic Acids Res 9: 5785-5795.

Blanc H, Wright CT, Bibb MJ, Wallace DC, Clayton DA. 1981b. Mitochondrial DNA of chloramphenicol-resistant mouse cells contains a single nucleotide change in the region encoding the $3^{\prime}$ end of the large ribosomal RNA. Proc Natl Acad Sci 78: 3789-3793.

Booker LM, Habermacher GM, Jessie BC, Sun QC, Baumann AK, Amin M, Lim SD, Fernandez-Golarz C, Lyles RH, Brown $\mathrm{MD}$, et al. 2006. North American white mitochondrial haplogroups in prostate and renal cancer. J Urol 175: 468-472.

Brandon M, Baldi P, Wallace DC. 2006. Mitochondrial mutations in cancer. Oncogene 25: 4647-4662.

Brower JV, Rodic N, Seki T, Jorgensen M, Fliess N, Yachnis AT, McCarrey JR, Oh SP, Terada N. 2007. Evolutionarily conserved mammalian adenine nucleotide translocase 4 is essential for spermatogenesis. I Biol Chem 282: 2965829666.

Brown MD, Torroni A, Reckord CL, Wallace DC. 1995. Phylogenetic analysis of Leber's hereditary optic neuropathy mitochondrial DNA's indicates multiple independent occurrences of the common mutations. Hum Mutat 6: 311-325.

Brown MD, Sun F, Wallace DC. 1997. Clustering of Caucasian Leber hereditary optic neuropathy patients containing the 11778 or 14484 mutations on an mtDNA lineage. Am J Hum Genet 60: 381-387.

Brown MD, Starikovskaya E, Derbeneva O, Hosseini S, Allen JC, Mikhailovskaya IE, Sukernik RI, Wallace DC. 2002. The role of mtDNA background in disease expression: A new primary LHON mutation associated with Western Eurasian haplogroup J. Hum Genet 110: 130-138.

Bunn CL, Wallace DC, Eisenstadt JM. 1974. Cytoplasmic inheritance of chloramphenicol resistance in mouse tissue culture cells. Proc Natl Acad Sci 71: 1681-1685.

Bunn CL, Wallace DC, Eisenstadt JM. 1977. Mitotic segregation of cytoplasmic determinants for chloramphenicol resistance in mammalian cells. I: Fusions with mouse cell lines. Somatic Cell Genet 3: 71-92.

Cai J, Wallace DC, Zhivotovsky B, Jones DP. 2000. Separation of cytochrome c-dependent caspase activation from thiol-disulfide redox change in cells lacking mitochondrial DNA. Free Radic Biol Med 29: 334-342.

Carrieri G, Bonafe M, De Luca M, Rose G, Varcasia O, Bruni A, Maletta R, Nacmias B, Sorbi S, Corsonello F, et al. 2001. Mitochondrial DNA haplogroups and APOE4 allele are nonindependent variables in sporadic Alzheimer's disease. Hum Genet 108: 194-198.

Carrozzo R, Dionisi-Vici C, Steuerwald U, Lucioli S, Deodato F, Di Giandomenico S, Bertini E, Franke B, Kluijtmans LA, Meschini MC, et al. 2007. SUCLA2 mutations are associated with mild methylmalonic aciduria, Leigh-like encephalomyopathy, dystonia and deafness. Brain 130: 862-874.

Chagnon P, Gee M, Filion M, Robitaille Y, Belouchi M, Gauvreau D. 1999. Phylogenetic analysis of the mitochondrial genome indicates significant differences between patients with Alzheimer disease and controls in a French-Canadian founder population. Am J Med Genet 85: 20-30.

Chen H, Detmer SA, Ewald AJ, Griffin EE, Fraser SE, Chan DC. 2003. Mitofusins Mfn1 and Mfn2 coordinately regulate mitochondrial fusion and are essential for embryonic development. J Cell Biol 160: 189-200.

Chen H, Chomyn A, Chan DC. 2005. Disruption of fusion results in mitochondrial heterogeneity and dysfunction. J Biol Chem 280: 26185-26192. 
Chen H, McCaffery JM, Chan DC. 2007. Mitochondrial fusion protects against neurodegeneration in the cerebellum. Cell 130: $548-562$.

Cheng EH, Sheiko TV, Fisher JK, Craigen WJ, Korsmeyer SJ. 2003. VDAC2 inhibits BAK activation and mitochondrial apoptosis. Science 301: 513-517.

Chomyn A, Mariottini P, Cleeter WJ, Ragan CI, Matsuno-Yagi A, Hatefi Y, Doolittle RF, Attardi G. 1985. Six unidentified reading frames of human mitochondrial DNA encode components of the respiratory-chain NADH dehydrogenase. Nature 314: 592-597.

Chomyn A, Cleeter WJ, Ragan CI, Riley M, Doolittle RF, Attardi G. 1986. URF6, last unidentified reading frame of human mtDNA, codes for an NADH dehydrogenase subunit. Science 234: 614-618.

Cipolat S, Martins de Brito O, Dal Zilio B, Scorrano L. 2004. OPA1 requires mitofusin 1 to promote mitochondrial fusion. Proc Natl Acad Sci 101: 15927-15932.

Clayton DA. 2003. Mitochondrial DNA replication: What we know. IUBMB Life 55: 213-217.

Corral-Debrinski M, Stepien G, Shoffner JM, Lott MT, Kanter K, Wallace DC. 1991. Hypoxemia is associated with mitochondrial DNA damage and gene induction. Implications for cardiac disease. JAMA 266: 1812-1816.

Corral-Debrinski M, Horton T, Lott MT, Shoffner JM, Beal MF, Wallace DC. 1992. Mitochondrial DNA deletions in human brain: Regional variability and increase with advanced age. Nat Genet 2: 324-329.

Corral-Debrinski M, Horton T, Lott MT, Shoffner JM, McKee AC, Beal MF, Graham BH, Wallace DC. 1994. Marked changes in mitochondrial DNA deletion levels in Alzheimer brains. Genomics 23: 471-476.

Cortopassi GA, Arnheim N. 1990. Detection of a specific mitochondrial DNA deletion in tissues of older humans. Nucleic Acids Res 18: 6927-6933.

Coskun PE, Beal MF, Wallace DC. 2004. Alzheimer's brains harbor somatic mtDNA control-region mutations that suppress mitochondrial transcription and replication. Proc Natl Acad Sci 101: 10726-10731.

Crispim D, Canani LH, Gross JL, Tschiedel B, Souto KE, Roisenberg I. 2006. The European-specific mitochondrial cluster $\mathrm{J} / \mathrm{T}$ could confer an increased risk of insulinresistance and type 2 diabetes: An analysis of the m.4216T $>\mathrm{C}$ and m.4917A > G variants. Ann Hum Genet 70: 488 495.

Dairaghi DJ, Shadel GS, Clayton DA. 1995. Addition of a 29 residue carboxyl-terminal tail converts a simple HMG boxcontaining protein into a transcriptional activator. J Mol Biol 249: $11-28$.

Darvishi K, Sharma S, Bhat AK, Rai E, Bamezai RN. 2007. Mitochondrial DNA G10398A polymorphism imparts maternal Haplogroup $\mathrm{N}$ a risk for breast and esophageal cancer. Cancer Lett 249: 249-255.

Davies VI, Hollins AJ, Piechota MJ, Yip W, Davies JR, White KE, Nicols PP, Boulton ME, Votruba M. 2007. Opal deficiency in a mouse model of autosomal dominant optic atrophy impairs mitochondrial morphology, optic nerve structure and visual function. Hum Mol Genet 16: 1307-1318.

De Benedictis G, Rose G, Carrieri G, De Luca M, Falcone E, Passarino G, Bonafe M, Monti D, Baggio G, Bertolini S, et al. 1999. Mitochondrial DNA inherited variants are associated with successful aging and longevity in humans. FASEB I 13: 1532-1536.

Delettre C, Lenaers G, Griffoin JM, Gigarel N, Lorenzo C, Belenguer P, Pelloquin L, Grosgeorge I, Turc-Carel C, Perret E, et al. 2000. Nuclear gene OPA1, encoding a mitochondrial dynamin-related protein, is mutated in dominant optic atrophy. Nat Genet 26: 207-210.

Dell'agnello C, Leo S, Agostino A, Szabadkai G, Tiveron C, Zulian A, Prelle A, Roubertoux P, Rizzuto R, Zeviani M. 2007. Increased longevity and refractoriness to $\mathrm{Ca}^{2+}$-dependent neurodegeneration in Surf1 knockout mice. Hum Mol Genet 16: 431-444.

Denaro M, Blanc H, Johnson MJ, Chen KH, Wilmsen E, Cavalli Sforza LL, Wallace DC. 1981. Ethnic variation in Hpa 1 endonuclease cleavage patterns of human mitochondrial DNA. Proc Natl Acad Sci 78: 5768-5772.

Diaz F, Thomas CK, Garcia S, Hernandez D, Moraes CT. 2005. Mice lacking COX10 in skeletal muscle recapitulate the phenotype of progressive mitochondrial myopathies associated with cytochrome c oxidase deficiency. Hum Mol Genet 14: $2737-2748$

Diaz F, Garcia S, Hernandez D, Regev A, Rebelo A, Oca-Cossio J, Moraes CT. 2008. Pathophysiology and fate of hepatocytes in a mouse model of mitochondrial hepatopathies. Gut 57: 232-242.

DiMauro S. 1993. Mitochondrial encephalomyopathies. In The molecular and genetic basis of neurological disease (eds. SB Rosenberg, et al.), pp. 665-694. Butterworth-Heinemann, Stoneham, MA.

Ekstrand MI, Terzioglu M, Galter D, Zhu S, Hofstetter C, Lindqvist E, Thams S, Bergstrand A, Hansson FS, Trifunovic A, et al. 2007. Progressive parkinsonism in mice with respiratory-chain-deficient dopamine neurons. Proc Natl Acad Sci 104: 1325-1330.

Elchuri S, Oberley TD, Qi W, Eisenstein RS, Jackson Roberts L, Van Remmen H, Epstein CJ, Huang TT. 2005. CuZnSOD deficiency leads to persistent and widespread oxidative damage and hepatocarcinogenesis later in life. Oncogene 24: $367-380$.

Enerback S, Jacobsson A, Simpson EM, Guerra C, Yamashita H, Harper ME, Kozak LP. 1997. Mice lacking mitochondrial uncoupling protein are cold-sensitive but not obese. Nature 387: 90-94.

Esposito LA, Melov S, Panov A, Cottrell BA, Wallace DC. 1999. Mitochondrial disease in mouse results in increased oxidative stress. Proc Natl Acad Sci 96: 4820-4825.

Esposito LA, Kokoszka JE, Waymire KG, Cottrell B, MacGregor GR, Wallace DC. 2000. Mitochondrial oxidative stress in mice lacking the glutathione peroxidase-1 gene. Free Radic Biol Med 28: 754-766.

Evans AR, Limp-Foster M, Kelley MR. 2000. Going APE over ref-1. Mutat Res 461: 83-108.

Falkenberg M, Gaspari M, Rantanen A, Trifunovic A, Larsson NG, Gustafsson CM. 2002. Mitochondrial transcription factors B1 and B2 activate transcription of human mtDNA. Nat Genet 31: 289-294.

Falkenberg M, Larsson NG, Gustafsson CM. 2007. DNA replication and transcription in mammalian mitochondria. Annu Rev Biochem 76: 679-699.

Fan W, Waymire K, Narula N, Li P, Rocher C, Coskun PE, Vannan MA, Narula J, MacGregor GR, Wallace DC. 2008. A mouse model of mitochondrial disease reveals germline selection against severe mtDNA mutations. Science 319: 958-962.

Ferris SD, Sage RD, Wilson AC. 1982. Evidence from mtDNA sequences that common laboratory strains of inbred mice are descended from a single female. Nature 295: 163-165.

Fisher RP, Lisowsky T, Parisi MA, Clayton DA. 1992. DNA wrapping and bending by a mitochondrial high mobility group-like transcriptional activator protein. I Biol Chem 267: 3358-3367. 
Freeman HC, Hugill A, Dear NT, Ashcroft FM, Cox RD. 2006. Deletion of nicotinamide nucleotide transhydrogenase: A new quantitive trait locus accounting for glucose intolerance in C57BL/6J mice. Diabetes 55: 2153-2156.

Fuku N, Park KS, Yamada Y, Nishigaki Y, Cho YM, Matsuo H, Segawa T, Watanabe S, Kato K, Yokoi K, et al. 2007. Mitochondrial hplogroup N9a confers resistance against type 2 diabetes in Asians. Am J Hum Genet 80: 407-415.

Fukui H, Diaz F, Garcia S, Moraes CT. 2007. Cytochrome c oxidase deficiency in neurons decreases both oxidative stress and amyloid formation in a mouse model of Alzheimer's disease. Proc Natl Acad Sci 104: 14163-14168.

Gandre-Babbe S, van der Bliek AM. 2008. The novel tail-anchored membrane protein Mff controls mitochondrial and peroxisomal fission in mammalian cells. Mol Biol Cell 19: 2402-2412.

Ghezzi D, Marelli C, Achilli A, Goldwurm S, Pezzoli G, Barone P, Pellecchia MT, Stanzione P, Brusa L, Bentivoglio AR, et al. 2005. Mitochondrial DNA haplogroup $\mathrm{K}$ is associated with a lower risk of Parkinson's disease in Italians. Eur I Hum Genet 13: 748-752.

Giles RE, Blanc H, Cann HM, Wallace DC. 1980. Maternal inheritance of human mitochondrial DNA. Proc Natl Acad Sci 77: 6715-6719.

Goto Y, Nonaka I, Horai S. 1990. A mutation in the tRNA ${ }^{\text {Leu(UUR) }}$ gene associated with the MELAS subgroup of mitochondrial encephalomyopathies. Nature 348: 651-653.

Gottlieb E, Tomlinson IP. 2005. Mitochondrial tumour suppressors: A genetic and biochemical update. Nat Rev Cancer 5: 857-866.

Graham BH, Waymire KG, Cottrell B, Trounce IA, MacGregor GR, Wallace DC. 1997. A mouse model for mitochondrial myopathy and cardiomyopathy resulting from a deficiency in the heart/skeletal muscle isoform of the adenine nucleotide translocator. Nat Genet 16: 226-234.

Hansen JM, Go YM, Jones DP. 2006. Nuclear and mitochondrial compartmentation of oxidative stress and redox signaling. Annu Rev Pharmacol Toxicol 46: 215-234.

Hashimoto Y, Niikura T, Tajima H, Yasukawa T, Sudo H, Ito Y, Kita Y, Kawasumi M, Kouyama K, Doyu M, et al. 2001. A rescue factor abolishing neuronal cell death by a wide spectrum of familial Alzheimer's disease genes and A $\beta$. Proc Natl Acad Sci 98: 6336-6341.

Hashizume K, Hirasawa M, Imamura Y, Noda S, Shimizu T, Shinoda K, Kurihara T, Noda K, Ozawa Y, Ishida S, et al. 2008. Retinal dysfunction and progressive retinal cell death in SOD1-deficient mice. Am J Pathol 172: 1325-1331.

Heddi A, Stepien G, Benke PJ, Wallace DC. 1999. Coordinate induction of energy gene expression in tissues of mitochondrial disease patients. I Biol Chem 274: 22968-22976.

Hendrickson SL, Hutcheson HB, Ruiz-Pesini E, Poole JC, Lautenberger J, Sezgin E, Kingsley L, Goedert JJ, Vlahov D, Donfield S, et al. 2008. Mitochondrial DNA haplogroups influence AIDS progression. AIDS 22: 2429-2439.

Hendrickson SL, Kingsley LA, Ruiz-Pesini E, Poole JC, Jacobson LP, Palella FJ, Bream JH, Wallace DC, O'Brien SJ. 2009. Mitochondrial DNA haplogroups influence lipoatrophy after highly active anti-retroviral therapy. I Acquir Immune Defic Syndr 51: 111-116.

Holt IJ, Harding AE, Morgan-Hughes JA. 1988. Deletions of muscle mitochondrial DNA in patients with mitochondrial myopathies. Nature 331: 717-719.

Holt IJ, Harding AE, Petty RK, Morgan-Hughes JA. 1990. A new mitochondrial disease associated with mitochondrial DNA heteroplasmy. Am J Hum Genet 46: 428-433.

Horton TM, Graham BH, Corral-Debrinski M, Shoffner JM, Kaufman AE, Beal BF, Wallace DC. 1995. Marked increase in mitochondrial DNA deletion levels in the cerebral cortex of Huntington's Disease patients. Neurology 45: 1879-1883.

Howell N. 1990. Glycine-231 residue of the mouse mitochondrial protonmotive cytochrome b: Mutation to aspartic acid deranges electron transport. Biochemistry 29: 8970-8977.

Howell N, Gilbert K. 1988. Mutational analysis of the mouse mitochondrial cytochrome b gene. J Mol Biol 203: 607-618.

Howell N, Appel J, Cook JP, Howell B, Hauswirth WW. 1987. The molecular basis of inhibitor resistance in a mammalian mitochondrial cytochrome b mutant. J Biol Chem 262: 24112414.

Huang TT, Naeemuddin M, Elchuri S, Yamaguchi M, Kozy HM, Carlson EJ, Epstein CJ. 2006. Genetic modifiers of the phenotype of mice deficient in mitochondrial superoxide dismutase. Hum Mol Genet 15: 1187-1194.

Hussein MR. 2005. Apoptosis in the ovary: Molecular mechanisms. Hum Reprod Update 11: 162-177.

Imamura Y, Noda S, Hashizume K, Shinoda K, Yamaguchi M, Uchiyama S, Shimizu T, Mizushima Y, Shirasawa T, Tsubota K. 2006. Drusen, choroidal neovascularization, and retinal pigment epithelium dysfunction in SOD1-deficient mice: A model of age-related macular degeneration. Proc Natl Acad Sci 103: 11282-11287.

Inoue K, Nakada K, Ogura A, Isobe K, Goto Y, Nonaka I, Hayashi J-I. 2000. Generation of mice with mitochondrial dysfunction by introducing mouse mtDNA carrying a deletion into zygotes. Nat Genet 26: 176-181.

Ishikawa K, Takenaga K, Akimoto M, Koshikawa N, Yamaguchi A, Imanishi H, Nakada K, Honma Y, Hayashi J. 2008. ROSgenerating mitochondrial DNA mutations can regulate tumor cell metastasis. Science 320: 661-664.

Ivanova R, Lepage V, Charron D, Schachter F. 1998. Mitochondrial genotype associated with French Caucasian centenarians. Gerontology 44: 349.

Jacobsson A, Stadler U, Glotzer MA, Kozak LP. 1985. Mitochondrial uncoupling protein from mouse brown fat. Molecular cloning, genetic mapping, and mRNA expression. I Biol Chem 260: 16250-16254.

James DI, Parone PA, Mattenberger Y, Martinou JC. 2003. hFis1, a novel component of the mammalian mitochondrial fission machinery. J Biol Chem 278: 36373-36379.

Jenuth JP, Peterson AC, Fu K, Shoubridge EA. 1996. Random genetic drift in the female germline explains the rapid segregation of mammalian mitochondrial DNA. Nat Genet 14: $146-151$.

Jones DP. 2006. Disruption of mitochondrial redox circuitry in oxidative stress. Chem Biol Interact 163: 38-53.

Jones MM, Manwaring N, Wang JJ, Rochtchina E, Mitchell P, Sue CM. 2007. Mitochondrial DNA haplogroups and agerelated maculopathy. Arch Ophthalmol 125: 1235-1240.

Kapsa R, Thompson GN, Thorburn DR, Dahl HH, Marzuki S, Byrne E, Blok RB. 1994. A novel mtDNA deletion in an infant with Pearson syndrome. J Inherit Metab Dis 17: 521-526.

Kasahara A, Ishikawa $K$, Yamaoka $M$, Ito $M$, Watanabe $N$, Akimoto M, Sato A, Nakada K, Endo H, Suda Y, et al. 2006. Generation of trans-mitochondrial mice carrying homoplasmic mtDNA with a missense mutation in a structural gene using ES cells. Hum Mol Genet 15: 871-881.

Kaukonen J, Amati P, Suomalainen A, Rotig A, Antozzi C, Salvi F, Weissenbach J, Peltonen L, Zeviani M. 1995. Identification of a second autosomal locus predisposing to multiple deletions of mitochondrial DNA. Am J Hum Genet 57: A216.

Kaukonen J, Juselius JK, Tiranti V, Kyttala A, Zeviani M, Comi GP, Keranen S, Peltonen L, Suomalainen A. 2000. Role of adenine nucleotide translocator 1 in mtDNA maintenance. Science 289: 782-785. 
Kelley MR, Parsons SH. 2001. Redox regulation of the DNA repair function of the human AP endonuclease Ape1/ref-1. Antioxid Redox Signal 3: 671-683.

Khusnutdinova E, Gilyazova I, Ruiz-Pesini E, Derbeneva O, Khusainova R, Khidiyatova I, Magzhanov R, Wallace DC. 2008. Ancient polymorphisms and recent mutations in Russian Tatar mitochondrial DNAs significantly modify Parkinson Disease risk. Ann NY Acad Sci (in press).

King MP, Attardi G. 1989. Human cells lacking mtDNA: Repopulation with exogenous mitochondria by complementation. Science 246: 500-503.

Kokoszka JE, Coskun P, Esposito L, Wallace DC. 2001. Increased mitochondrial oxidative stress in the Sod $2^{+/-}$mouse results in the age-related decline of mitochondrial function culminating in increased apoptosis. Proc Natl Acad Sci 98: 22782283.

Kokoszka JE, Waymire KG, Levy SE, Sligh JE, Cai J, Jones DP, MacGregor GR, Wallace DC. 2004. The ADP/ATP translocator is not essential for the mitochondrial permeability transition pore. Nature 427: 461-465.

Kozak LP, Britton JH, Kozak UC, Wells JM. 1988. The mitochondrial uncoupling protein gene. Correlation of exon structure to transmembrane domains. I Biol Chem 263: 12274-12277.

Krauskopf A, Eriksson O, Craigen WJ, Forte MA, Bernardi P. 2006. Properties of the permeability transition in $\mathrm{VDACl}^{-1-}$ mitochondria. Biochim Biophys Acta 1757: 590-595.

Kraytsberg Y, Kudryavtseva E, McKee AC, Geula C, Kowall NW, Khrapko K. 2006. Mitochondrial DNA deletions are abundant and cause functional impairment in aged human substantia nigra neurons. Nat Genet 38: 518-520.

Kruse SE, Watt WC, Marcinek DJ, Kapur RP, Schenkman KA, Palmiter RD. 2008. Mice with mitochondrial complex I deficiency develop a fatal encephalomyopathy. Cell Metab 7: 312-320.

Kujoth GC, Hiona A, Pugh TD, Someya S, Panzer K, Wohlgemuth SE, Hofer T, Seo AY, Sullivan R, Jobling WA, et al. 2005. Mitochondrial DNA mutations, oxidative stress, and apoptosis in mammalian aging. Science 309: 481-484.

Larsson NG, Wang I, Wilhelmsson H, Oldfors A, Rustin P, Lewandoski M, Barsh GS, Clayton DA. 1998. Mitochondrial transcription factor A is necessary for mtDNA maintenance and embryogenesis in mice. Nat Genet 18: 231-236.

Lebovitz RM, Zhang H, Vogel H, Cartwright J Jr, Dionne L, Lu N, Huang S, Matzuk MM. 1996. Neurodegeneration, myocardial injury, and perinatal death in mitochondrial superoxide dismutase-deficient mice. Proc Natl Acad Sci 93: 9782-9787.

Levy SE, Chen Y, Graham BH, Wallace DC. 2000. Expression and sequence analysis of the mouse adenine nucleotide translocase 1 and 2 genes. Gene 254: 57-66.

Li Y, Huang TT, Carlson EJ, Melov S, Ursell PC, Olson JL, Noble LJ, Yoshimura MP, Berger C, Chan PH, et al. 1995. Dilated cardiomyopathy and neonatal lethality in mutant mice lacking manganese superoxide dismutase. Nat Genet 11: 376-381.

Li K, Li Y, Shelton JM, Richardson JA, Spencer E, Chen ZJ, Wang X, Williams RS. 2000. Cytochrome c deficiency causes embryonic lethality and attenuates stress-induced apoptosis. Cell 101: 389-399.

Linder T, Park CB, Asin-Cayuela J, Pellegrini M, Larsson NG, Falkenberg M, Samuelsson T, Gustafsson CM. 2005. A family of putative transcription termination factors shared amongst metazoans and plants. Curr Genet 48: 265-269.

Luft R. 1994. The development of mitochondrial medicine. Proc Natl Acad Sci 91: 8731-8738.
Luft R, Ikkos D, Palmieri G, Ernster L, Afzelius BA. 1962. A case of severe hypermetabolism of nonthyroid origin with a defect in the maintenance of mitochondrial respiratory control: A correlated clinical, biochemical, and morphological study. J Clin Invest 41: 1776-1804.

MacGregor GR, Fan WW, Waymire KG, Wallace DC. 2006. Generating animal models of human mitochondrial genetic disease using mouse ES cells. In Embryonic stem cells (ed. E Notarianni, MJ Evans), pp. 72-104. Oxford University Press, New York.

Mandel H, Szargel R, Labay V, Elpeleg O, Saada A, Shalata A, Anbinder Y, Berkowitz D, Hartman C, Barak M, et al. 2001. The deoxyguanosine kinase gene is mutated in individuals with depleted hepatocerebral mitochondrial DNA. Nat Genet 29: 337-341.

Martin M, Cho J, Cesare AJ, Griffith JD, Attardi G. 2005. Termination factor-mediated DNA loop between termination and initiation sites drives mitochondrial rRNA synthesis. Cell 123: 1227-1240.

McCord JM. 2000. The evolution of free radicals and oxidative stress. Am J Med Genet 108: 652-659.

McCulloch V, Shadel GS. 2003. Human mitochondrial transcription factor $\mathrm{B} 1$ interacts with the $\mathrm{C}$-terminal activation region of h-mtTFA and stimulates transcription independently of its RNA methyltransferase activity. Mol Cell Biol 23: 58165824.

McKenzie M, Trounce IA, Cassar CA, Pinkert CA. 2004. Production of homoplasmic xenomitochondrial mice. Proc Natl Acad Sci 101: 1685-1690.

Melov S, Coskun P, Patel M, Tunistra R, Cottrell B, Jun AS, Zastawny TH, Dizdaroglu M, Goodman SI, Huang T, et al. 1999. Mitochondrial disease in superoxide dismutase 2 mutant mice. Proc Natl Acad Sci 96: 846-851.

Michikawa Y, Mazzucchelli F, Bresolin N, Scarlato G, Attardi G. 1999. Aging-dependent large accumulation of point mutations in the human mtDNA control region for replication. Science 286: 774-779.

Mishmar D, Ruiz-Pesini EE, Golik P, Macaulay V, Clark AG, Hosseini S, Brandon M, Easley K, Chen E, Brown MD, et al. 2003. Natural selection shaped regional $m t D N A$ variation in humans. Proc Natl Acad Sci 100: 171-176.

Mita S, Schmidt B, Schon EA, DiMauro S, Bonilla E. 1989. Detection of 'deleted' mitochondrial genomes in cytochrome-c oxidase-deficient muscle fibers of a patient with Kearns-Sayre syndrome. Proc Natl Acad Sci 86: 9509-9513.

Mohlke KL, Jackson AU, Scott LJ, Peck EC, Suh YD, Chines PS, Watanabe RM, Buchanan TA, Conneely KN, Erdos MR, et al. 2005. Mitochondrial polymorphisms and susceptibility to type 2 diabetes-related traits in Finns. Hum Genet 118: 245254.

Montoya J, Ojala D, Attardi G. 1981. Distinctive features of the 5 '-terminal sequences of the human mitochondrial mRNAs. Nature 290: 465-470.

Moraes CT, DiMauro S, Zeviani M, Lombes A, Shanske S, Miranda AF, Nakase H, Bonilla E, Werneck LC, Servidei S, et al. 1989. Mitochondrial DNA deletions in progressive external ophthalmoplegia and Kearns-Sayre syndrome. $N$ Engl J Med 320: 1293-1299.

Murdock D, Boone BE, Esposito LA, Wallace DC. 1999. Upregulation of nuclear and mitochondrial genes in the skeletal muscle of mice lacking the heart/muscle isoform of the adenine nucleotide translocator. I Biol Chem 274: 1442914433.

Murdock DG, Christacos NC, Wallace DC. 2000. The agerelated accumulation of a mitochondrial DNA control region mutation in muscle, but not brain, detected by a sensitive 
PNA-directed PCR clamping based method. Nucleic Acids Res 28: 4350-4355.

Nachman MW, Brown WM, Stoneking M, Aquadro CF. 1996. Nonneutral mitochondrial DNA variation in humans and chimpanzees. Genetics 142: 953-963.

Nakada K, Sato A, Yoshida K, Morita T, Tanaka H, Inoue SI, Yonekawa H, Hayashi JI. 2006. Mitochondria-related male infertility. Proc Natl Acad Sci 103: 15148-15153.

Nakagawa T, Shimizu S, Watanabe T, Yamaguchi O, Otsu K, Yamagata $\mathrm{H}$, Inohara H, Kubo T, Tsujimoto Y. 2005. Cyclophilin D-dependent mitochondrial permeability transition regulates some necrotic but not apoptotic cell death. Nature 434: 652-658.

Nicholls DG, Locke RM. 1984. Thermogenic mechanisms in brown fat. Physiol Rev 64: 1-64.

Niemi AK, Hervonen A, Hurme M, Karhunen PJ, Jylha M, Majamaa K. 2003. Mitochondrial DNA polymorphisms associated with longevity in a Finnish population. Hum Genet 112: 29-33.

Nishigaki Y, Yamada Y, Fuku N, Matsuo H, Segawa T, Watanabe S, Kato K, Yokoi K, Yamaguchi S, Nozawa Y, et al. 2007. Mitochondrial haplogroup N9b is protective against myocardial infarction in Japanese males. Hum Genet 120: 827-836.

Nishino I, Spinazzola A, Hirano M. 1999. Thymidine phosphorylase gene mutations in MNGIE, a human mitochondrial disorder. Science 283: 689-692.

Ojala D, Montoya J, Attardi G. 1981. tRNA punctuation model of RNA processing in human mitochondria. Nature 290: 470-474.

Oliver NA, Wallace DC. 1982. Assignment of two mitochondrially synthesized polypeptides to human mitochondrial DNA and their use in the study of intracellular mitochondrial interaction. Mol Cell Biol 2: 30-41.

Palmieri L, Alberio S, Pisano I, Lodi T, Meznaric-Petrusa M, Zidar J, Santoro A, Scarcia P, Fontanesi F, Lamantea E, et al. 2005. Complete loss-of-function of the heart/muscle-specific adenine nucleotide translocator is associated with mitochondrial myopathy and cardiomyopathy. Hum Mol Genet 14: 3079-3088.

Park CB, Asin-Cayuela J, Camara Y, Shi Y, Pellegrini M, Gaspari M, Wibom R, Hultenby K, Erdjument-Bromage H, Tempst P, et al. 2007. MTERF3 is a negative regulator of mammalian mtDNA transcription. Cell 130: 273-285.

Petros JA, Baumann AK, Ruiz-Pesini E, Amin MB, Sun CQ, Hall J, Lim S, Issa MM, Flanders WD, Hosseini SH, et al. 2005. mtDNA mutations increase tumorigenicity in prostate cancer. Proc Natl Acad Sci 102: 719-724.

Potluri P, Davila A, Ruiz-Pesini E, Mishmar D, O'Hearn S, Hancock S, Simon MC, Scheffler I, Wallace DC, Procaccio V. 2009. Progressive complex I-specific neurodegenerative disease caused by faulty nuclear-cytoplasmic interaction. Mol Genet Metab 96: 189-195.

Procaccio V, Wallace DC. 2004. Late-onset Leigh syndrome in a patient with mitochondrial complex I NDUFS8 mutations. Neurology 62: 1899-1901.

Raby BA, Klanderman B, Murphy A, Mazza S, Camargo CA Jr, Silverman EK, Weiss ST. 2007. A common mitochondrial haplogroup is associated with elevated total serum IgE levels. I Allergy Clin Immunol 120: 351-358.

Radi R, Turrens JF, Chang LY, Bush KM, Crapo JD, Freeman BA. 1991. Detection of catalase in rat heart mitochondria. J Biol Chem 266: 22028-22034.

Radi R, Bush KM, Freeman BA. 1993a. The role of cytochrome c and mitochondrial catalase in hydroperoxide-induced heart mitochondrial lipid peroxidation. Arch Biochem Biophys 300: 409-415.
Radi R, Sims S, Cassina A, Turrens JF. 1993b. Roles of catalase and cytochrome $\mathrm{c}$ in hydroperoxide-dependent lipid peroxidation and chemiluminescence in rat heart and kidney mitochondria. Free Radic Biol Med 15: 653-659.

Reaume AG, Elliott JL, Hoffman EK, Kowall NW, Ferrante RJ, Siwek DF, Wilcox HM, Flood DG, Beal MF, Brown RH Jr, et al. 1996. Motor neurons in $\mathrm{Cu} / \mathrm{Zn}$ superoxide dismutasedeficient mice develop normally but exhibit enhanced cell death after axonal injury. Nat Genet 13: 43-47.

Reichling S, Ridley RG, Patel HV, Harley CB, Freeman KB. 1987. Loss of brown adipose tissue uncoupling protein mRNA on deacclimation of cold-exposed rats. Biochem Biophys Res Commun 142: 696-701.

Ridley RG, Patel HV, Gerber GE, Morton RC, Freeman KB. 1986. Complete nucleotide and derived amino acid sequence of cDNA encoding the mitochondrial uncoupling protein of rat brown adipose tissue: Lack of a mitochondrial targeting presequence. Nucleic Acids Res 14: 4025-4035.

Rodic N, Oka M, Hamazaki T, Murawski MR, Jorgensen M, Maatouk DM, Resnick JL, Li E, Terada N. 2005. DNA methylation is required for silencing of ant4, an adenine nucleotide translocase selectively expressed in mouse embryonic stem cells and germ cells. Stem Cells 23: 1314-1323.

Rose G, Passarino G, Carrieri G, Altomare K, Greco V, Bertolini S, Bonafe M, Franceschi C, De Benedictis G. 2001. Paradoxes in longevity: Sequence analysis of mtDNA haplogroup J in centenarians. Eur J Hum Genet 9: 701-707.

Rotig A, Colonna M, Blanche S, Fischer A, LeDeist F, Frezal J, Saudubray JM, Munnich A. 1988. Deletion of blood mitochondrial DNA in pancytopenia. Lancet 2: 567-568.

Rotig A, Bourgeron T, Chretien D, Rustin P, Munnich A. 1995. Spectrum of mitochondrial DNA rearrangements in the Pearson marrow-pancreas syndrome. Hum Mol Genet 4: 1327-1330.

Ruiz-Pesini E, Wallace DC. 2006. Evidence for adaptive selection acting on the tRNA and rRNA genes of the human mitochondrial DNA. Hum Mutat 27: 1072-1081.

Ruiz-Pesini E, Mishmar D, Brandon M, Procaccio V, Wallace DC. 2004. Effects of purifying and adaptive selection on regional variation in human mtDNA. Science 303: 223-226.

Saada A, Shaag A, Mandel H, Nevo Y, Eriksson S, Elpeleg O. 2001. Mutant mitochondrial thymidine kinase in mitochondrial DNA depletion myopathy. Nat Genet 29: 342-344.

Sampson MJ, Decker WK, Beaudet AL, Ruitenbeek W, Armstrong D, Hicks MJ, Craigen WJ. 2001. Immotile sperm and infertility in mice lacking mitochondrial voltage-dependent anion channel type 3. J Biol Chem 276: 39206-39212.

Sato A, Nakada K, Shitara H, Kasahara A, Yonekawa H, Hayashi J. 2007. Deletion-mutant mtDNA increases in somatic tissues but decreases in female germ cells with age. Genetics 177: 2031-2037.

Saxena R, de Bakker PI, Singer K, Mootha V, Burtt N, Hirschhorn JN, Gaudet D, Isomaa B, Daly MJ, Groop L, et al. 2006. Comprehensive association testing of common mitochondrial DNA variation in metabolic disease. Am I Hum Genet 79: 54-61.

Schriner SE, Ogburn CE, Smith AC, Newcomb TG, Ladiges WC, Dolle ME, Vijg J, Fukuchi K, Martin GM. 2000. Levels of DNA damage are unaltered in mice overexpressing human catalase in nuclei. Free Radic Biol Med 29: 664-673.

Schriner SE, Linford NJ, Martin GM, Treuting P, Ogburn CE, Emond M, Coskun PE, Ladiges W, Wolf N, Van Remmen H, et al. 2005. Extension of murine life span by overexpression of catalase targeted to mitochondria. Science 308: 1909-1911.

Schwartz M, Vissing J. 2002. Paternal inheritance of mitochondrial DNA. N Engl J Med 347: 576-580. 
Shoffner JM, Lott MT, Lezza AM, Seibel P, Ballinger SW, Wallace DC. 1990. Myoclonic epilepsy and ragged-red fiber disease (MERRF) is associated with a mitochondrial DNA tRNA ${ }^{\text {Lys }}$ mutation. Cell 61: 931-937.

Shoffner JM, Brown MD, Torroni A, Lott MT, Cabell MR, Mirra SS, Beal MF, Yang C, Gearing M, Salvo R, et al. 1993. Mitochondrial DNA variants observed in Alzheimer disease and Parkinson disease patients. Genomics 17: 171-184.

Silva JP, Kohler M, Graff C, Oldfors A, Magnuson MA, Berggren PO, Larsson NG. 2000. Impaired insulin secretion and $\beta$-cell loss in tissue-specific knockout mice with mitochondrial diabetes. Nat Genet 26: 336-340.

Sligh JE, Levy SE, Waymire KG, Allard P, Dillehay DL, Nusinowitz S, Heckenlively JR, MacGregor GR, Wallace DC. 2000. Maternal germ-line transmission of mutant mtDNAs from embryonic stem cell-derived chimeric mice. Proc Natl Acad Sci 97: 14461-14466.

Smirnova E, Griparic L, Shurland DL, van der Bliek AM. 2001. Dynamin-related protein Drp1 is required for mitochondrial division in mammalian cells. Mol Biol Cell 12: 2245-2256.

Soong NW, Hinton DR, Cortopassi G, Arnheim N. 1992. Mosaicism for a specific somatic mitochondrial DNA mutation in adult human brain. Nat Genet 2: 318-323.

Spelbrink JN, Li FY, Tiranti V, Nikali K, Yuan QP, Tariq M, Wanrooij S, Garrido N, Comi G, Morandi L, et al. 2001. Human mitochondrial DNA deletions associated with mutations in the gene encoding Twinkle, a phage T7 gene 4-like protein localized in mitochondria. Nat Genet 28: 223-231.

Spiegelman BM, Heinrich R. 2004. Biological control through regulated transcriptional coactivators. Cell 119: 157-167.

Stewart JB, Freyer C, Elson JL, Wredenberg A, Cansu Z, Trifunovic A, Larsson NG. 2008. Strong purifying selection in transmission of mammalian mitochondrial DNA. PLOS Biol 6: e10. doi: 10.1371/journal.pbio.0060010.

Subramaniam V, Golik P, Murdock DG, Levy S, Kerstann KW, Coskun PE, Melkonian GA, Wallace DC. 2008. MITOCHIP assessment of differential gene expression in the skeletal muscle of Antl knockout mice: Coordinate regulation of OXPHOS, antioxidant, and apoptotic genes. Biochim Biophys Acta 1777: 666-675.

Tanaka M, Gong IS, Zhang J, Yoneda M, Yagi K. 1998. Mitochondrial genotype associated with longevity. Lancet 351: $185-186$.

Tanaka M, Gong J, Zhang J, Yamada Y, Borgeld HJ, Yagi K. 2000. Mitochondrial genotype associated with longevity and its inhibitory effect on mutagenesis. Mech Ageing Dev 116: 6576.

Tilly JL, Tilly KI. 1995. Inhibitors of oxidative stress mimic the ability of follicle-stimulating hormone to suppress apoptosis in cultured rat ovarian follicles. Endocrinology 136: 242-252.

Tiranti V, Hoertnagel K, Carrozzo R, Galimberti C, Munaro M, Granatiero M, Zelante L, Gasparini P, Marzella R, Rocchi M, et al. 1998. Mutations of SURF-1 in Leigh Disease associated with cytochrome c oxidase deficiency. Am I Hum Genet 63: 1609-1621.

Torroni A, Petrozzi M, D’Urbano L, Sellitto D, Zeviani M, Carrara F, Carducci C, Leuzzi V, Carelli V, Barboni P, et al. 1997. Haplotype and phylogenetic analyses suggest that one European-specific mtDNA background plays a role in the expression of Leber hereditary optic neuropathy by increasing the penetrance of the primary mutations 11778 and 14484. Am I Hum Genet 60: 1107-1121.

Trifunovic A, Wredenberg A, Falkenberg M, Spelbrink JN, Rovio AT, Bruder CE, Bohlooly YM, Gidlof S, Oldfors A, Wibom R, et al. 2004. Premature ageing in mice expressing defective mitochondrial DNA polymerase. Nature 429: 417-423.
Trounce I, Schmiedel J, Yen HC, Hosseini S, Brown MD, Olson JI, Wallace DC. 2000. Cloning of neuronal mtDNA variants in cultured cells by synaptosome fusion with mtDNA-less cells. Nucleic Acids Res 28: 2164-2170.

Tsai-Turton M, Luderer U. 2006. Opposing effects of glutathione depletion and follicle-stimulating hormone on reactive oxygen species and apoptosis in cultured preovulatory rat follicles. Endocrinology 147: 1224-1236.

Tyynismaa H, Mjosund KP, Wanrooij S, Lappalainen I, Ylikallio E, Jalanko A, Spelbrink JN, Paetau A, Suomalainen A. 2005. Mutant mitochondrial helicase Twinkle causes multiple mtDNA deletions and a late-onset mitochondrial disease in mice. Proc Natl Acad Sci 102: 17687-17692.

Udar N, Atilano SR, Memarzadeh M, Boyer DS, Chwa M, Lu S, Maguen B, Langberg J, Coskun P, Wallace DC, et al. 2009. Mitochondrial DNA haplogroups associated with age-related macular degeneration. Invest Ophthalmol Vis Sci 50: 29662974.

van der Walt JM, Nicodemus KK, Martin ER, Scott WK, Nance MA, Watts RL, Hubble JP, Haines JL, Koller WC, Lyons K, et al. 2003. Mitochondrial polymorphisms significantly reduce the risk of Parkinson disease. Am J Hum Genet 72: 804-811.

van der Walt JM, Dementieva YA, Martin ER, Scott WK, Nicodemus KK, Kroner CC, Welsh-Bohmer KA, Saunders AM, Roses AD, Small GW, et al. 2004. Analysis of European mitochondrial haplogroups with Alzheimer disease risk. Neurosci Lett 365: 28-32.

Van Goethem G, Dermaut B, Lofgren A, Martin J, Van Broeckhoven C. 2001. Mutation of POLG is associated with progressive external ophthalmoplegia characterized by mtDNA deletions. Nat Genet 28: 211-212.

Vermulst M, Bielas JH, Kujoth GC, Ladiges WC, Rabinovitch PS, Prolla TA, Loeb LA. 2007. Mitochondrial point mutations do not limit the natural lifespan of mice. Nat Genet 39: 540543.

Vermulst M, Bielas JH, Loeb LA. 2008a. Quantification of random mutations in the mitochondrial genome. Methods 46: $263-268$.

Vermulst M, Wanagat J, Kujoth GC, Bielas JH, Rabinovitch PS, Prolla TA, Loeb LA. 2008b. DNA deletions and clonal mutations drive premature aging in mitochondrial mutator mice. Nat Genet 40: 392-394.

Vidal-Puig AJ, Grujic D, Zhang CY, Hagen T, Boss O, Ido Y, Szczepanik A, Wade J, Mootha V, Cortright R, et al. 2000. Energy metabolism in uncoupling protein 3 gene knockout mice. J Biol Chem 275: 16258-16266.

Wallace DC. 1981. Assignment of the chloramphenicol resistance gene to mitochondrial deoxyribonucelic acid and analysis of its expression in cultured human cells. Mol Cell Biol 1: 697-710.

Wallace DC. 1992. Mitochondrial genetics: A paradigm for aging and degenerative diseases? Science 256: 628-632.

Wallace DC. 2005a. Mitochondria and cancer: Warburg address. Cold Spring Harb Symp Quant Biol 70: 363-374.

Wallace DC. 2005b. The mitochondrial genome in human adaptive radiation and disease: On the road to therapeutics and performance enhancement. Gene 354: 169-180.

Wallace DC. 2005c. A mitochondrial paradigm of metabolic and degenerative diseases, aging, and cancer: A dawn for evolutionary medicine. Annu Rev Genet 39: 359-407.

Wallace, D.C. 2007. Why do we have a maternally inherited mitochondrial DNA? Insights from evolutionary medicine Ann Rev Biochem 76: 781-821.

Wallace DC. 2008. Mitochondria as chi. Genetics 179: 727-735.

Wallace DC, Eisenstadt JM. 1979. The expression of cytoplasmically inherited genes for chloramphenicol resistance in 
interspecific somatic cell hybrids and cybrids. Somatic Cell Genet 5: 373-396.

Wallace DC, Lott MT. 2002. Mitochondrial genes in degenerative diseases, cancer and aging. In Emery and Rimoin's principles and practice of medical genetics (eds. DL Rimoin, et al.), pp. 299-409. Churchill Livingstone, London.

Wallace DC, Bunn CL, Eisenstadt JM. 1975. Cytoplasmic transfer of chloramphenicol resistance in human tissue culture cells. J Cell Biol 67: 174-188.

Wallace DC, Bunn CL, Eisenstadt JM. 1977. Mitotic segregation of cytoplasmic inherited genes for chloramphenicol resistance in mammalian cells. II: Fusions with human cell lines. Somatic Cell Genet 3: 93-119.

Wallace DC, Singh G, Lott MT, Hodge JA, Schurr TG, Lezza AM, Elsas LJ, Nikoskelainen EK. 1988a. Mitochondrial DNA mutation associated with Leber's hereditary optic neuropathy. Science 242: 1427-1430.

Wallace DC, Zheng X, Lott MT, Shoffner JM, Hodge JA, Kelley RI, Epstein CM, Hopkins LC. 1988b. Familial mitochondrial encephalomyopathy (MERRF): Genetic, pathophysiological, and biochemical characterization of a mitochondrial DNA disease. Cell 55: 601-610.

Wallace DC, Brown MD, Lott MT. 1999. Mitochondrial DNA variation in human evolution and disease. Gene 238: 211230.

Wallace DC, Lott MT, Brown MD, Kerstann K. 2001. Mitochondria and neuro-ophthalmological diseases. In The metabolic and molecular basis of inherited disease (eds. CR Scriver, et al.), pp. 2425-2512. McGraw-Hill, New York.

Wallace DC, Ruiz-Pesini E, Mishmar D. 2003. mtDNA variation, climatic adaptation, degenerative diseases, and longevity. Cold Spring Harb Symp Quant Biol 68: 479-486.

Wallace DC, Chuang L-M, Wang PH, Chang Y-C, Derbeneva O, Mishmar D, Lvova M. 2007a. Asian mitochondrial DNA (mtDNA) lineages are associated with altered risk of developing type 2 diabetes and metabolic syndrome. Am J Hum Genet Abststract 1549. http://www.ashg.org/genetics/ashg07s/ f21033.htm.

Wallace DC, Lott MT, Procaccio V. 2007b. Mitochondrial genes in degenerative diseases, cancer and aging. In Emery and Rimoin's principles and practice of medical genetics, 5th ed. (eds. DL Rimoin, et al.), pp. 194-298. Churchill Livingstone Elsevier, Philadelphia, PA.

Wang JM, Wilhelmsson H, Graff C, Li H, Oldfors A, Rustin P, Bruning JC, Kahn CR, Clayton DA, Barsh GS, et al. 1999. Dilated cardiomyopathy and atrioventricular conduction blocks induced by heart-specific inactivation of mitochondrial DNA gene expression. Nat Genet 21: 133-137.

Wredenberg A, Wibom R, Wilhelmsson H, Graff C, Wiener HH, Burden SJ, Oldfors A, Westerblad H, Larsson NG. 2002. Increased mitochondrial mass in mitochondrial myopathy mice. Proc Natl Acad Sci 99: 15066-15071.

Yoon Y, Krueger EW, Oswald BJ, McNiven MA. 2003. The mitochondrial protein hFis1 regulates mitochondrial fission in mammalian cells through an interaction with the dynaminlike protein DLP1. Mol Cell Biochem 23: 5409-5420.

Zamzami N, Kroemer G. 2001. The mitochondrion in apoptosis: How Pandora's box opens. Nat Rev Mol Cell Biol 2: 67-71.

Zhu Z, Yao J, Johns T, Fu K, De Bie I, Macmillan C, Cuthbert AP, Newbold RF, Wang J, Chevrette M, et al. 1998. SURF1, encoding a factor involved in the biogenesis of cytochrome c oxidase, is mutated in Leigh syndrome. Nat Genet 20: 337343.

Zuchner S, Mersiyanova IV, Muglia M, Bissar-Tadmouri N, Rochelle J, Dadali EL, Zappia M, Nelis E, Patitucci A, Senderek J, et al. 2004. Mutations in the mitochondrial
GTPase mitofusin 2 cause Charcot-Marie-Tooth neuropathy type 2A. Nat Genet 36: 449-451. 


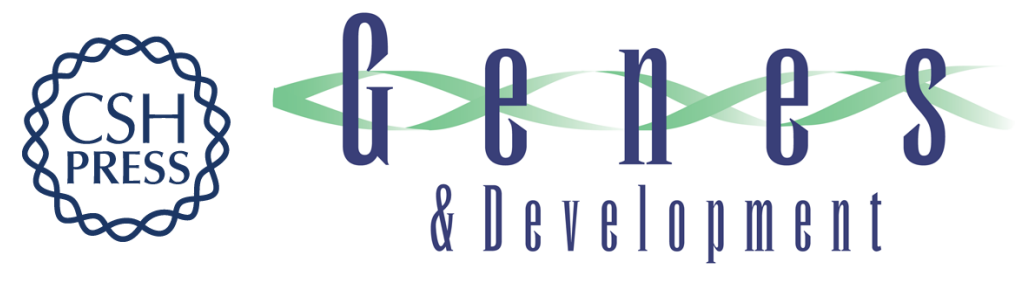

\section{The pathophysiology of mitochondrial disease as modeled in the mouse}

Douglas C. Wallace and WeiWei Fan

Genes Dev. 2009, 23:

Access the most recent version at doi:10.1101/gad.1784909

References This article cites 215 articles, 70 of which can be accessed free at: http://genesdev.cshlp.org/content/23/15/1714.full.html\#ref-list-1

License

Email Alerting

Receive free email alerts when new articles cite this article - sign up in the box at the top Service right corner of the article or click here.

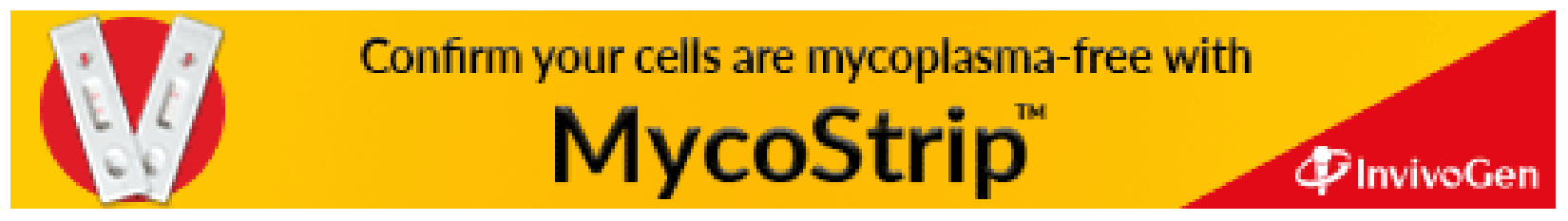

